Federal Reserve Bank of Dallas

Globalization and Monetary Policy Institute

Working Paper No. 242

http://www.dallasfed.org/assets/documents/institute/wpapers/2015/0242.pdf

\title{
Country-Specific Oil Supply Shocks and the Global Economy: A Counterfactual Analysis*
}

\author{
Kamiar Mohaddes \\ Girton College and University of Cambridge \\ M. Hashem Pesaran \\ USC Dornsife INET, University of Southern California and Trinity College
}

May 2015

\begin{abstract}
This paper investigates the global macroeconomic consequences of country-specific oilsupply shocks. Our contribution is both theoretical and empirical. On the theoretical side, we develop a model for the global oil market and integrate this within a compact quarterly model of the global economy to illustrate how our multi-country approach to modelling oil markets can be used to identify country-specific oil-supply shocks. On the empirical side, estimating the GVAR-Oil model for 27 countries/regions over the period 1979Q2 to 2013Q1, we show that the global economic implications of oil-supply shocks (due to, for instance, sanctions, wars, or natural disasters) vary considerably depending on which country is subject to the shock. In particular, we find that adverse shocks to Iranian oil output are neutralized in terms of their effects on the global economy (real outputs and financial markets) mainly due to an increase in Saudi Arabian oil production. In contrast, a negative shock to oil supply in Saudi Arabia leads to an immediate and permanent increase in oil prices, given that the loss in Saudi Arabian production is not compensated for by the other oil producers. As a result, a Saudi Arabian oil supply shock has significant adverse effects for the global economy with real GDP falling in both advanced and emerging economies, and large losses in real equity prices worldwide.
\end{abstract}

JEL codes: C32, E17, F44, F47, O53, Q43

\footnotetext{
* Kamiar Mohaddes, Girton College, Cambridge CB3 OJG, UK. 44-0-1223-335-267. km418@cam.ac.uk. M. Hashem Pesaran, Department of Economics, University of Southern California, 3620 South Vermont Avenue, Kaprielian Hall 300, Los Angeles, CA 90089-0253. pesaran@usc.edu. We are grateful to Robert Blotevogel, Alexander Chudik, Massoud Karshenas, Lutz Kilian, Rania Al Mashat, Mehdi Raissi, Alessandro Rebucci, Ron Smith, Wessel Vermeulen, and seminar participants at the Graduate Institute of International and Development Studies (Geneva), as well as participants at the Third International Conference on the Iranian Economy, Boston College, October 2014, and the Economic Research Forum 21st Annual Conference, Tunisia, March 2015, for constructive comments and suggestions. The views in this paper are those of the authors and do not necessarily reflect the views of the Federal Reserve Bank of Dallas or the Federal Reserve System.
} 


\section{Introduction}

This paper investigates the economic consequences of country-specific oil supply shocks for the global economy in terms of their impacts on real output, oil prices and financial markets. It complements the extensive literature that exists on the effects of shocks to the aggregate oil supply in the world economy. See, for example, Kilian (2008b, 2009), Hamilton (2009), and Cashin et al. (2014). An analysis of the effects of country-specific oil supply shocks is required to answer counterfactual questions regarding the possible macroeconomic effects of oil sanctions, or region-specific supply disruptions due to wars or natural disasters. ${ }^{1}$ To this end, we first develop a model of the global oil market and derive an oil price equation which takes account of developments in the world economy as well as the prevailing oil supply conditions. We then integrate this within a compact quarterly model of the global economy comprising 27 countries, with the euro area being treated as a single economy, using a dynamic multi-country framework first advanced by Pesaran et al. (2004), known as the Global VAR (or GVAR for short). This approach allows us to analyze the international macroeconomic transmission of the effects of country-specific oil supply shocks, taking into account not only the direct exposure of countries to the shocks but also the indirect effects through secondary or tertiary channels.

The individual country-specific models are solved in a global setting where core macroeconomic variables of each economy (real GDP, inflation, real exchange rate, short and long-term interest rates, and oil production) are related to corresponding foreign variables, (also known as "star" variables) constructed to match the international trade pattern of the country under consideration. Star variables serve as proxies for common unobserved factors and affect the global economy in addition to the set common observable variables (oil prices and global equity prices). We estimate the 27 country-specific vector autoregressive models with foreign variables (VARX* models) over the period 1979Q2 to 2013Q1 separately and then combine these with the estimates from the global oil market, which we refer to as the GVAR-Oil model. The combined model is used for a number of counterfactual exercises. In particular, we examine the direct and indirect effects of shocks to Iranian and Saudi Arabian oil output on the world economy, on a country-by-country basis, and provide the time profile of the effects of country-specific oil shocks on oil prices, real outputs across countries, and real equity prices.

The paper also makes a theoretical contribution to the analysis of oil shocks. In particular, we propose a new scheme for identification of country-specific supply shocks based on the

\footnotetext{
${ }^{1}$ See Hamilton (2013) for the history of the oil industry with a particular focus on oil shocks. On historical oil shocks, see also Kilian (2008b) and Kilian and Murphy (2014).
} 
assumption that changes in an individual country's oil production are unimportant relative to changes in the world oil supplies, and as a result the correlation of oil prices and countryspecific oil supply shocks tends to zero for a sufficiently large number of oil producers. We show that such an identification procedure is applicable even if the country-specific oil supply shocks are weakly correlated, in the sense defined by Chudik et al. (2011). ${ }^{2}$ To allow for the possible cross-country oil supply spillover effects we make use of structural generalized impulse response functions based on historically estimated covariances of the country-specific oil supply shocks. Our identification approach differs from the literature, which considers identification of global supply shocks typically by imposing sign restrictions on the structural parameters of a three equation VAR model in oil prices, world real output, and global oil production. See, for instance, Kilian and Murphy (2012, 2014), Baumeister and Peersman (2013b), and Cashin et al. (2014).

Our findings suggest that a one-standard-error adverse shock to Iranian oil output, equivalent to a fall in the Iranian oil supply of around $16 \%$ in the first four quarters, is neutralized in terms of its effects on the global economy. This is mainly due to an increase in Saudi Arabian oil production to compensate for the loss in OPEC supply and to stabilize the oil markets, which is borne out by the recent episode of oil sanctions against Iran by the U.S. and European countries. This outcome is made possible due to the large Saudi Arabian spare capacity, which allows it to act as a swing producer at the global level. However, a negative shock to Iranian oil supply does lead to a fall in Iranian real output of around $6 \%$ in the short-run, and rebounds somewhat ending with a drop in real output of around 3.5\% over the long run, as the Iranian economy adjusts to the new reduced level of oil income. Moreover, Saudi Arabia tends to benefit from a negative shock to Iranian oil production. In the long run Saudi real output increases by $3.1 \%$ in response to the negative shock to Iran's oil output.

In contrast, a one-standard-error adverse shock to oil production in Saudi Arabia (around $11 \%$ per quarter) has far-reaching implications for oil markets and the global economy. A Saudi negative oil supply shock causes oil prices to rise substantially and reach $22 \%$ above their pre-shock levels in the long run. This is not surprising, given that most of the other oil exporters are producing at (or near) capacity and cannot increase their production to compensate for the loss in Saudi Arabian oil supply. As a result, the shock to Saudi oil output has significant effects for the global economy not only in terms of real output, which falls in both advanced (including the U.K. and the U.S.) and emerging economies, but also in terms of financial markets as global real equity prices fall by around $9 \%$ in the long run.

\footnotetext{
${ }^{2}$ The country-specific oil supply shocks, $v_{i t}$, for $i=1,2, \ldots, N$, are said to be cross-sectionally weakly correlated if $\sup _{j} \sum_{i=1}^{N}\left|\operatorname{cov}\left(v_{i t}, v_{j t}\right)\right|<K<\infty$ for all $N$.
} 
While there is a large body of literature investigating the effects of oil shocks on the macroeconomy, most studies have focused on a handful of industrialized/OECD countries with the analysis being mainly done in isolation from the rest of the world. Although some of these papers aim to identify the underlying source of the oil shock (demand versus supply), most of these oil-price shocks are taken to be global in nature rather than originating from a particular oil-producing country (or region). Moreover, the focus of the literature has been predominantly on net oil importers. See, for example, Hamilton (2003, 2009), Kilian (2008a, 2008b), Blanchard and Gali (2009), and Peersman and Van Robays (2012). In fact, in the majority of cases these studies have looked at the impact of oil shocks exclusively on the United States, as in Kilian (2009), who using a structural VAR model, decomposes oil-price shocks into three types: global oil-supply shock, global oil-demand shock driven by economic activity, and an oil-specific demand shock driven by expectations about future changes in global oil market conditions.

More recently, however, a number of papers have examined the effects of oil shocks on major oil exporters (located in the Middle East, Africa and Latin America) as well as many emerging and developing countries. For instance, Esfahani et al. (2014), conducting a country-by-country VARX* analysis, investigate the direct effects of oil-revenue shocks on domestic output for nine major oil exporters, of which six are OPEC members (Iran, Kuwait, Libya, Nigeria, Saudi Arabia, and Venezuela), one is a former OPEC member (Indonesia), and the remaining two are OECD oil exporters (Mexico and Norway). ${ }^{3}$ Kilian et al. (2009) examine the effects of different types of oil-price shocks on the external balances of net oil exporters/importers. Finally, Cashin et al. (2014) employ a set of sign restrictions on the impulse responses of a GVAR model, as well as bounds on impact price elasticities of oil supply and oil demand, to discriminate between supply-driven and demand-driven global oil-price shocks, and to study the time profile of their macroeconomic effects across a wide range of countries and variables. ${ }^{4}$

In this paper, we extend the literature in a number of respects. Firstly, we model global oil markets separately from the country-specific VARX* models, by specifying an oil price equation which takes account of global demand conditions as well as oil supply conditions across some of the major oil producing countries. Secondly, we illustrate how the multicountry approach to modelling oil markets can be used to identify country-specific oil-supply shocks. Thirdly, by including oil supplies in the country-specific models for the oil producing countries we are able to identify and investigate not only the implications of country-specific

\footnotetext{
${ }^{3}$ Chapter 4 of International Monetary Fund (2012) provides a discussion of the effects of commodity price shocks on commodity exporters, using the methodology in Kilian (2009).

${ }^{4}$ See also Cavalcanti et al. (2011a, 2011b, 2014) for recent panel studies taking into account cross-country heterogeneity and cross-sectional dependence.
} 
oil supply shocks on the global economy in terms of real GDP, but also their effects on global financial markets and oil prices. This is in contrast to most of the literature that focuses on the identification of global supply shocks, rather than shocks to a specific country or region. Finally, given the importance of U.S. equity markets in global finance, we model global financial markets within the United States VARX* model, thus explicitly using the U.S. model as a transmission mechanism for identifying the effects of oil supply shocks on real equity prices, and the second round effects of changes in real equity prices on real outputs and oil prices.

The remainder of the paper is organized as follows. Section 2 outlines a multi-country approach for identification of country-specific oil supply shocks. Section 3 develops a model for global oil markets and integrates it within a compact quarterly model of the global economy. Section 4 provides estimates of the GVAR-Oil model, namely the oil price equation and country-specific VARX* models inclusive of country-specific oil supply equations. In Section 5 the GVAR-Oil model is used to investigate the global macroeconomic consequences of adverse shocks to Iranian and Saudi Arabian oil supplies. Finally, Section 6 offers some concluding remarks.

\section{Identification of country-specific oil supply shocks}

In this section we abstract from dynamics, common factors and financial variables and consider the simultaneous determination of the oil price, $p_{t}^{o}$, aggregate oil supply, $q_{t}^{o}$, and real world income, $y_{t}$, by the following three equations

$$
\begin{aligned}
& p_{t}^{o}=\alpha y_{t}+\beta q_{t}^{o}+u_{t}^{o}, \\
& q_{t}^{o}=\psi p_{t}^{o}+\varphi y_{t}+v_{t} \\
& y_{t}=\theta p_{t}^{o}+\gamma q_{t}^{o}+\varepsilon_{t}
\end{aligned}
$$

where $u_{t}^{o}, v_{t}$, and $\varepsilon_{t}$ are the "structural" shocks, which are assumed to be uncorrelated. As is well known, in this unrestricted formulation the structural parameters, $\alpha, \beta, \psi, \varphi, \theta$, and $\gamma$, and hence the structural shocks, are not identified. In the literature the oil supply and demand shocks are identified using a structural VAR approach, in some cases making use of $a$ priori sign restrictions. See, for instance, Baumeister and Peersman (2013a, 2013b), Cashin et al. (2014), Chudik and Fidora (2012), Kilian (2009), Kilian and Murphy (2012, 2014), and Peersman and Van Robays (2012). However, this approach only helps in identifying global supply shocks rather than shocks originating from a particular country or a region.

To consider identification of country-specific oil supply shocks, we utilize a multi-country 
framework where we assume that $q_{t}^{o}$ and $y_{t}$ are aggregates over a large number of countries. To this end we suppose that

$$
\begin{aligned}
& y_{t}=\sum_{i=1}^{N} w_{i} y_{i t}, \\
& q_{t}^{o}=\sum_{i=1}^{N} w_{i}^{o} q_{i t}^{o},
\end{aligned}
$$

where $y_{i t}$ and $q_{i t}^{o}$ are the real income and quantity of oil output of country $i$ at time $t$, respectively, and $w_{i}$ and $w_{i}^{o}$ are the weights attached to country $i^{\prime} s$ real income and oil production in the construction of the world GDP and oil supply. Moreover, we assume that the individual country contributions to $y_{t}$ and $q_{t}^{o}$ are of order $1 / N$, and in particular the weights, $w_{i}$ and $w_{i}^{o}$, satisfy the following granularity conditions

$$
\begin{aligned}
\|\mathbf{w}\| & =O\left(N^{-\frac{1}{2}}\right), \\
\frac{w_{i}}{\|\mathbf{w}\|} & =O\left(N^{-\frac{1}{2}}\right) \text { for all } i
\end{aligned}
$$

where $\mathbf{w}=\left(w_{1}, w_{2}, \ldots, w_{N}\right)^{\prime}$, or $\mathbf{w}^{o}=\left(w_{1}^{o}, w_{2}^{o}, \ldots, w_{N}^{o}\right)^{\prime}$, are $N \times 1$ vectors of weights.

We now replace equations (2) and (3) with the following disaggregated system of equations:

$$
\begin{aligned}
& q_{i t}^{o}=\psi_{i} p_{t}^{o}+\varphi_{i} y_{i t}+v_{i t}, \text { for } i=1,2, \ldots, N, \\
& y_{i t}=\theta_{i} p_{t}^{o}+\gamma_{i} q_{i t}^{o}+\varepsilon_{i t}, \text { for } i=1,2, \ldots, N,
\end{aligned}
$$

where $\mathbf{v}_{t}=\left(v_{1 t}, v_{2 t}, \ldots, v_{N t}\right)^{\prime}$ and $\varepsilon_{t}=\left(\varepsilon_{1 t}, \varepsilon_{2 t}, \ldots, \varepsilon_{N t}\right)^{\prime}$ are $N \times 1$ vectors of country-specific oil supply and real income shocks. One could also allow for the effects of technological changes on the oil supply conditions in the above model, but such extensions do not affect our analysis of identification of oil supply shocks so long as the additional factors are uncorrelated with $v_{i t}$. The same argument can also be made with regard to the real output equation, (9). Furthermore, as it is done in the case of the GVAR-Oil specification in Section 3, individual real output equations can be considered as a part of country-specific VAR or VARX* models where other variables such as interest rates, inflation and exchange rates are also included in the analysis. But for the purpose of identification of oil supply shocks, $\mathbf{v}_{t}$, we abstract from such complications.

Along with the literature, we assume that the oil demand shock, $u_{t}^{o}$, the oil supply shocks, $\mathbf{v}_{t}$, and real income shocks, $\varepsilon_{t}$, are uncorrelated, but allow the oil supply shocks (and real 
income shocks) to be cross-sectionally weakly correlated. This is formalized in the following assumption.

Assumption 1: Consider the $N$ country-specific oil supply shocks, $\mathbf{v}_{t}=\left(v_{1 t}, v_{2 t}, \ldots, v_{N t}\right)^{\prime}$, the $N$ country-specific real output shocks, $\varepsilon_{t}=\left(\varepsilon_{1 t}, \varepsilon_{2 t}, \ldots, \varepsilon_{N t}\right)^{\prime}$, and the oil demand shock, $p_{t}^{0}$, defined by equations (1), (8) and (9), respectively, and let $E\left(\mathbf{v}_{t} \mathbf{v}_{t}^{\prime}\right)=\boldsymbol{\Sigma}_{v v}$ and $E\left(\varepsilon_{t} \varepsilon_{t}^{\prime}\right)=$ $\boldsymbol{\Sigma}_{\varepsilon \varepsilon}$. Suppose that

$$
\begin{aligned}
E\left(u_{t}^{o} \mathbf{v}_{t}\right) & =0, E\left(u_{t}^{o} \varepsilon_{t}\right)=0, E\left(\mathbf{v}_{t} \varepsilon_{t}^{\prime}\right)=0, E\left[\left(u_{t}^{o}\right)^{2}\right]<K<\infty, \\
\lambda_{\max }\left(\boldsymbol{\Sigma}_{v v}\right) & <K<\infty, \text { and } \lambda_{\max }\left(\boldsymbol{\Sigma}_{\varepsilon \varepsilon}\right)<K<\infty,
\end{aligned}
$$

where $\lambda_{\max }(\mathbf{A})$ denotes the largest eigenvalue of matrix $\mathbf{A}$.

Assumption 2: The coefficients in (8) and (9) are bounded in $N$, namely

$$
\left|\psi_{i}\right|<K<\infty,\left|\varphi_{i}\right|<K<\infty,\left|\theta_{i}\right|<K<\infty,\left|\gamma_{i}\right|<K<\infty .
$$

Also

$$
1-\varphi_{i} \gamma_{i} \neq 0 \text {, for all } i,
$$

and $1-\alpha \bar{\mu}_{N}-\beta \bar{\mu}_{N}^{o} \neq 0$, where $\bar{\mu}_{N}$ and $\bar{\mu}_{N}^{o}$ are defined by (12) and (13) below, for all $N$ and as $N \rightarrow \infty$.

We are now ready to investigate the conditions under which $p_{t}^{0}$ can be treated as (weakly) exogenous, and country-specific supply shocks identified. To this end, solving for $q_{i t}^{o}$ and $y_{i t}$ in terms of $p_{t}^{o}$ we have

$$
\begin{aligned}
& q_{i t}^{o}=\left(\frac{\psi_{i}+\varphi_{i} \theta_{i}}{1-\varphi_{i} \gamma_{i}}\right) p_{t}^{o}+\left(\frac{1}{1-\varphi_{i} \gamma_{i}}\right)\left(v_{i t}+\varphi_{i} \varepsilon_{i t}\right), \\
& y_{i t}=\left(\frac{\gamma_{i} \psi_{i}+\theta_{i}}{1-\varphi_{i} \gamma_{i}}\right) p_{t}^{o}+\left(\frac{1}{1-\varphi_{i} \gamma_{i}}\right)\left(\gamma_{i} v_{i t}+\varepsilon_{i t}\right) .
\end{aligned}
$$

Aggregating over $i=1,2, \ldots, N$ and using equations (4) and (5) we obtain

$$
\begin{aligned}
& y_{t}=\bar{\mu}_{N} p_{t}^{o}+\bar{v}_{N t}+\bar{\varepsilon}_{N t}, \\
& q_{t}^{o}=\bar{\mu}_{N}^{o} p_{t}^{o}+\bar{v}_{N t}^{o}+\bar{\varepsilon}_{N t}^{o},
\end{aligned}
$$

where

$$
\bar{\mu}_{N}=\sum_{i=1}^{N} w_{i}\left(\frac{\gamma_{i} \psi_{i}+\theta_{i}}{1-\varphi_{i} \gamma_{i}}\right), \bar{v}_{N t}=\sum_{i=1}^{N} w_{i}\left(\frac{\gamma_{i} v_{i t}}{1-\varphi_{i} \gamma_{i}}\right), \bar{\varepsilon}_{N t}=\sum_{i=1}^{N} w_{i}\left(\frac{\varepsilon_{i t}}{1-\varphi_{i} \gamma_{i}}\right),
$$


and

$$
\bar{\mu}_{N}^{o}=\sum_{i=1}^{N} w_{i}^{o}\left(\frac{\psi_{i}+\varphi_{i} \theta_{i}}{1-\varphi_{i} \gamma_{i}}\right), \bar{v}_{N t}^{o}=\sum_{i=1}^{N} w_{i}^{o}\left(\frac{v_{i t}}{1-\varphi_{i} \gamma_{i}}\right), \bar{\varepsilon}_{N t}^{o}=\sum_{i=1}^{N} w_{i}^{o}\left(\frac{\varphi_{i} \varepsilon_{i t}}{1-\varphi_{i} \gamma_{i}}\right)
$$

Using these results in equation (1) we now have

$$
p_{t}^{o}=\frac{u_{t}^{o}+\alpha\left(\bar{v}_{N t}+\bar{\varepsilon}_{N t}\right)+\beta\left(\bar{v}_{N t}^{o}+\bar{\varepsilon}_{N t}^{o}\right)}{\left(1-\alpha \bar{\mu}_{N}-\beta \bar{\mu}_{N}^{o}\right)} .
$$

It is clear that $E\left(p_{t}^{o} v_{i t}\right) \neq 0$ and $E\left(p_{t}^{o} \varepsilon_{i t}\right) \neq 0$, when $N$ is finite, and as a result OLS regressions of $q_{i t}$ on $p_{t}^{0}$ and $y_{i t}$ will not yield consistent estimates of the oil supply shocks. But writing $\bar{v}_{N t}$ as $\bar{v}_{N t}=\mathbf{w}_{\gamma}^{\prime} \mathbf{v}_{t}$ where $\mathbf{w}_{\gamma}=\left(w_{1} \gamma_{1}, w_{2} \gamma_{2}, \ldots, w_{N} \gamma_{N}\right)^{\prime}$, we note that under Assumption $1 E\left(\bar{v}_{N t}\right)=0$, and

$$
\operatorname{Var}\left(\bar{v}_{N t}\right)=\mathbf{w}_{\gamma}^{\prime} \Sigma_{v v} \mathbf{w}_{\gamma} \leq \mathbf{w}_{\gamma}^{\prime} \mathbf{w}_{\gamma} \lambda_{\max }\left(\Sigma_{v v}\right)
$$

Therefore, under Assumption 2 and the granularity condition (6), we obtain

$$
\mathbf{w}_{\gamma}^{\prime} \mathbf{w}_{\gamma}=\sum_{i=1}^{N} \gamma_{i}^{2} w_{i}^{2} \leq \sup _{i}\left(\gamma_{i}^{2}\right)\|\mathbf{w}\|^{2}=O\left(N^{-1}\right)
$$

Hence, $\bar{v}_{N t}=O_{p}\left(N^{-1 / 2}\right)$. Similarly, it follows that $\bar{v}_{N t}^{o}=O_{p}\left(N^{-1 / 2}\right), \bar{\varepsilon}_{N t}=O_{p}\left(N^{-1 / 2}\right)$, and $\bar{\varepsilon}_{N t}^{o}=O_{p}\left(N^{-1 / 2}\right)$, and noting that by assumption $\left(1-\alpha \bar{\mu}_{N}-\beta \bar{\mu}_{N}^{o}\right) \neq 0$, then

$$
p_{t}^{o}=\frac{u_{t}^{o}}{\left(1-\alpha \bar{\mu}_{N}-\beta \bar{\mu}_{N}^{o}\right)}+O_{p}\left(N^{-1 / 2}\right)
$$

Therefore, under the standard assumption that the oil demand shock $\left(u_{t}^{o}\right)$ and the countryspecific oil supply shocks $\left(v_{i t}\right)$ are uncorrelated we have $\operatorname{Cov}\left(p_{t}^{o}, v_{i t}\right)=O_{p}\left(N^{-1 / 2}\right)$, for all $i$. Similarly, under the assumption that the oil demand shock and country-specific income shocks are uncorrelated we also have $\operatorname{Cov}\left(p_{t}^{o}, \varepsilon_{i t}\right)=O_{p}\left(N^{-1 / 2}\right)$, for all $i$. These results establish that when $N$ is sufficiently large and the granularity condition (6) is met, oil prices can be treated as exogenous in individual country oil supply and income equations. The granularity condition is likely to hold for all oil producers considered in the empirical section 4, with the possible exception of Saudi Arabia. In the empirical application we use weak exogeneity tests to check the validity of our maintained assumption that oil prices can be treated as exogenous in country-specific oil supply equations.

To identify oil supply shocks, $v_{i t}$, further restrictions are needed. But, given the global 
role played by the multi-national oil companies in exploration, development and production of oil across many countries, it is reasonable to assume that oil supply in individual countries are determined by the availability of oil reserves and geopolitical factors rather than countryspecific real incomes. This suggests setting $\varphi_{i}=0$. Under this restriction $v_{i t}$ can be identified by OLS regression of $q_{i t}$ on $p_{t}^{o}$. In the case of the more general set up used in the empirical application we consider the inclusion of other variables (such interest rates) in the countryspecific oil supply equations which could be important in capturing the inter-temporal aspects of the oil supply process as well.

\section{The GVAR-Oil model}

We now introduce deterministics, common factors and dynamics in the multi-country model. For the oil price equation we consider the general dynamic aggregate demand function for oil given by

$$
q_{t d}^{o}=a_{d}+\epsilon_{y} a_{y}(L) y_{t}-\epsilon_{p^{o}} a_{p}(L) p_{t}^{o}+\varepsilon_{d t},
$$

where $q_{t d}^{o}$ is the logarithm of world demand for oil, $y_{t}$ is a measure of world real income (in logs), $p_{t}^{o}$ is the logarithm of real oil prices, $a_{d}$ is a fixed constant, $a_{y}(L)$ and $a_{p}(L)$ are polynomials in the lag operator, $L$, whose coefficients add up to unity, namely

$$
\begin{aligned}
& a_{y}(L)=a_{y 0}+a_{y 1} L+a_{y 2} L^{2}+\ldots \\
& a_{p}(L)=a_{p 0}+a_{p 1} L+a_{p 2} L^{2}+\ldots
\end{aligned}
$$

with $a_{y}(1)=a_{p}(1)=1$. Hence, $\epsilon_{y}>0$ is the long-run income elasticity of demand for oil and $\epsilon_{p^{\circ}}>0$ is the long-run price elasticity of demand for oil. We further assume that oil prices adjust to the gap between demand and supply of oil as specified by

$$
\Delta p_{t}^{o}=a_{s}+\lambda\left(q_{t d}^{o}-q_{t}^{o}\right)+\varepsilon_{s t}
$$

where $\lambda$ measures the speed of the adjustment, $a_{s}$ is a fixed constant that captures the scarcity value of oil, and $\varepsilon_{s t}$ represents speculative oil price changes not related to the fundamental factors that drive oil demand and supply. The intercept $a_{s}$ could be a function of the interest rate as predicted by the Hotelling (1931) model. Combining the above two equations we obtain

$$
\Delta p_{t}^{o}=a_{s}+\lambda\left[a_{d}+\epsilon_{y} a_{y}(L) y_{t}-\epsilon_{p^{o}} a_{p}(L) p_{t}^{o}+\varepsilon_{d t}\right]-\lambda q_{t}^{o}+\varepsilon_{s t}
$$


or

$$
\Delta p_{t}^{o}=a_{p}+\lambda \epsilon_{y} a_{y}(L) y_{t}-\lambda \epsilon_{p^{o}} a_{p}(L) p_{t}^{o}-\lambda q_{t}^{o}+\varepsilon_{p t}
$$

where

$$
a_{p}=a_{s}+\lambda a_{d}, \text { and } \varepsilon_{p t}=\lambda \varepsilon_{d t}+\varepsilon_{s t} .
$$

Using (17) we can now solve for $p_{t}^{o}$ to obtain

$$
\begin{aligned}
p_{t}^{o}= & \left(\frac{1}{1+\lambda \epsilon_{p^{o}} a_{p 0}}\right) a_{p}+\left(\frac{1-\lambda \epsilon_{p^{o}} a_{p 1}}{1+\lambda \epsilon_{p^{o}} a_{p 0}}\right) p_{t-1}^{o}-\left(\frac{\lambda \epsilon_{p^{o}}}{1+\lambda \epsilon_{p^{o}} a_{p 0}}\right) \sum_{\ell=2}^{\infty} a_{p \ell} p_{t-\ell}^{o} \\
& +\left(\frac{\lambda \epsilon_{y}}{1+\lambda \epsilon_{p^{o}} a_{p 0}}\right) a_{y}(L) y_{t}-\left(\frac{\lambda}{1+\lambda \epsilon_{p^{o}} a_{p 0}}\right) q_{t}^{o}+\left(\frac{1}{1+\lambda \epsilon_{p^{o}} a_{p 0}}\right) \varepsilon_{p t},
\end{aligned}
$$

which is a standard autoregressive distributed lag (ARDL) model in oil prices, world real income and world oil supplies. It is easily established that the above specification reduces to (1) if we set $\alpha_{p}=0$ and abstract from the dynamics.

To analyze the international macroeconomic transmission of country-specific oil supply shocks, we now need to integrate the oil price equation (18) within a compact quarterly model of the global economy. To this end we utilize the Global VAR (GVAR) framework, which is a dynamic multi-country framework able to account not only for direct exposures of countries to oil shocks but also indirect effects through third markets, originally proposed by Pesaran et al. (2004) and further developed by Dees et al. (2007). To simplify the exposition we set all lag orders to unity and consider the simple dynamic oil price equation

$$
p_{t}^{o}=c_{p}+\phi_{1} p_{t-\ell}^{o}+\alpha_{1} y_{t-1}+\beta_{1} q_{t-1}^{o}+u_{t}^{o}
$$

where as before (see (4) and (5)),

$$
y_{t}=\sum_{i=1}^{N} \omega_{i} y_{i t}, \text { and } q_{t}^{o}=\sum_{i=1}^{N} \omega_{i}^{o} q_{i t}^{o}
$$

We model $y_{i t}$ and $q_{i t}^{o}$ in conjunction with other macro variables, specifically, we consider the following country-specific models

$$
\mathbf{x}_{i t}=\mathbf{a}_{i 0}+\mathbf{a}_{i 1} t+\boldsymbol{\Phi}_{i} \mathbf{x}_{i, t-1}+\boldsymbol{\Lambda}_{i 0} \mathbf{x}_{i t}^{*}+\boldsymbol{\Lambda}_{i 1} \mathbf{x}_{i, t-1}^{*}+\boldsymbol{\Upsilon}_{i 0} p_{t}^{o}+\boldsymbol{\Upsilon}_{i 1} p_{t-1}^{o}+\mathbf{u}_{i t},
$$

where $\mathbf{a}_{i 0}, \mathbf{a}_{i 1}, \boldsymbol{\Phi}_{i}, \boldsymbol{\Lambda}_{i 0}, \boldsymbol{\Lambda}_{i 1}, \boldsymbol{\Upsilon}_{i 0}$, and $\boldsymbol{\Upsilon}_{i 1}$ are vectors/matrices of fixed coefficients that vary across countries, $\mathbf{x}_{i t}$ is $k_{i} \times 1$ vector of country-specific endogenous variables, and $\mathbf{x}_{i t}^{*}$ is $k_{i}^{*} \times 1$ vector of country-specific weakly exogenous (or 'star' variables). The 'star' variables, $\mathbf{x}_{i t}^{*}$, are 
constructed using country-specific trade shares, and defined by

$$
\mathbf{x}_{i t}^{*}=\sum_{j=1}^{N} w_{i j} \mathbf{x}_{j t}
$$

where $w_{i j}, i, j=1,2, \ldots N$, are bilateral trade weights, with $w_{i i}=0$, and $\sum_{j=1}^{N} w_{i j}=1 .^{5}$

The country-specific VARX* models, (20), are combined with the oil price equation, (19), and solved for all the endogenous variables collected in the vector, $\mathbf{z}_{t}=\left(p_{t}^{0}, \mathbf{x}_{1 t}^{\prime}, \mathbf{x}_{2 t}^{\prime}, \ldots, \mathbf{x}_{N t}^{\prime}\right)^{\prime}=$ $\left(p_{t}^{o}, \mathbf{x}_{t}^{\prime}\right)^{\prime}$, We refer to this combined model as the GVAR-Oil model, which allows for a twoway linkage between the global economy and oil prices. Changes in the global economic conditions and oil supplies affect oil prices with a lag, with oil prices potentially influencing all country-specific variables. Similarly, changes in oil supplies, determined in country models for the major oil producers, are affected by oil prices and in turn affect oil prices with a lag as specified in the oil price equation, (19).

Although estimation is carried out on a country-by-country basis, the GVAR model is solved for oil prices and all country variables simultaneously, taking account of the fact that all variables are endogenous to the system as a whole. To solve for the endogenous variables, $\mathbf{z}_{t}$, using (21) we first note that $\mathbf{x}_{i t}^{*}=\mathbf{W}_{i} \mathbf{x}_{t}$, where $\mathbf{W}_{i}$ is a $k_{i}^{*} \times(k+1)$, matrix of fixed constants (which are either 0 or 1 or some pre-specified weights, $w_{i j}$ ), $k=\sum_{i=1}^{N} k_{i}$, $k_{i}^{*}=\operatorname{dim}\left(\mathbf{x}_{i t}^{*}\right)$. Stacking the country-specific models we now have

$$
\mathbf{x}_{t}=\boldsymbol{\varphi}_{t}+\mathbf{\Phi} \mathbf{x}_{t-1}+\mathbf{H}_{0} \mathbf{x}_{t}+\mathbf{H}_{1} \mathbf{x}_{t-1}+\Upsilon_{0} p_{t}^{o}+\Upsilon_{1} p_{t-1}^{o}+\mathbf{u}_{t}
$$

where

$$
\begin{gathered}
\boldsymbol{\Phi}=\left(\begin{array}{cccc}
\boldsymbol{\Phi}_{1} & \mathbf{0} & \cdots & \mathbf{0} \\
\mathbf{0} & \boldsymbol{\Phi}_{2} & \cdots & \mathbf{0} \\
\vdots & \vdots & \ddots & \vdots \\
\mathbf{0} & \mathbf{0} & \cdots & \boldsymbol{\Phi}_{N}
\end{array}\right), \mathbf{H}_{0}=\left(\begin{array}{c}
\boldsymbol{\Lambda}_{10} \mathbf{W}_{1} \\
\boldsymbol{\Lambda}_{20} \mathbf{W}_{2} \\
\vdots \\
\boldsymbol{\Lambda}_{N 0} \mathbf{W}_{N}
\end{array}\right), \mathbf{H}_{1}=\left(\begin{array}{c}
\boldsymbol{\Lambda}_{11} \mathbf{W}_{1} \\
\boldsymbol{\Lambda}_{21} \mathbf{W}_{2} \\
\vdots \\
\boldsymbol{\Lambda}_{N 1} \mathbf{W}_{N}
\end{array}\right), \boldsymbol{\Upsilon}_{0}=\left(\begin{array}{c}
\mathbf{a}_{10}+\mathbf{a}_{11} t \\
\mathbf{\Upsilon}_{20} \\
\vdots \\
\mathbf{a}_{20}+\mathbf{a}_{21} t \\
\vdots \\
\mathbf{\Upsilon}_{N 0}+\mathbf{a}_{N 1} t
\end{array}\right), \boldsymbol{\Upsilon}_{1}=\left(\begin{array}{c}
\boldsymbol{\Upsilon}_{11} \\
\boldsymbol{\Upsilon}_{21} \\
\vdots \\
\boldsymbol{\Upsilon}_{N 1}
\end{array}\right), \mathbf{u}_{t}=\left(\begin{array}{c}
\mathbf{u}_{1 t} \\
\mathbf{u}_{2 t} \\
\vdots \\
\mathbf{u}_{N t}
\end{array}\right)
\end{gathered}
$$

\footnotetext{
${ }^{5}$ The main justification for using bilateral trade weights, as opposed to financial weights for instance, is that the former have been shown to be the most important determinant of national business cycle comovements. See Baxter and Kouparitsas (2005), among others.
} 
We also note that the oil price equation can be written as

$$
p_{t}^{o}=c_{p}+\phi_{1} p_{t-1}^{o}+\left(\alpha_{1} \mathbf{w}_{y}^{\prime}+\beta_{1} \mathbf{w}_{q}^{\prime}\right) \mathbf{x}_{t-1}+u_{t}^{o}
$$

where $\mathbf{w}_{y}$ and $\mathbf{w}_{q}$ are $k \times 1$ vectors whose elements are either zero or is set equal to the weights $w_{i}$ or $w_{i}^{0}$, assigned to $y_{i t}$ or $q_{i t}^{o}$, as implied by (4) and (5), respectively. Combining the above oil price equation with the country specific models we obtain

$$
\left(\begin{array}{cc}
1 & 0 \\
-\mathbf{\Upsilon}_{0} & \mathbf{I}_{k}-\mathbf{H}_{0}
\end{array}\right)\left(\begin{array}{c}
p_{t}^{o} \\
\mathbf{x}_{t}
\end{array}\right)=\left(\begin{array}{c}
c_{p} \\
\boldsymbol{\varphi}_{t}
\end{array}\right)+\left(\begin{array}{cc}
\phi_{1} & \alpha_{1} \mathbf{w}_{y}^{\prime}+\beta_{1} \mathbf{w}_{q}^{\prime} \\
\mathbf{\Upsilon}_{1} & \mathbf{\Phi}+\mathbf{H}_{1}
\end{array}\right)\left(\begin{array}{c}
p_{t-1}^{o} \\
\mathbf{x}_{t-1}
\end{array}\right)+\left(\begin{array}{c}
u_{t}^{o} \\
\mathbf{u}_{t}
\end{array}\right)
$$

which can be written more compactly as

$$
\mathbf{G}_{0} \mathbf{z}_{t}=\mathbf{b}_{t}+\mathbf{G}_{1} \mathbf{z}_{t-1}+\mathbf{v}_{t}
$$

Under the assumption that $\mathbf{I}_{k}-\mathbf{H}_{0}$ is invertible the GVAR-Oil model has the following reduced form solution:

$$
\mathbf{z}_{t}=\mathbf{a}_{t}+\mathbf{F} \mathbf{z}_{t-1}+\boldsymbol{\xi}_{t}
$$

where

$$
\mathbf{a}_{t}=\mathbf{G}_{0}^{-1} \mathbf{a}_{t}, \mathbf{F}=\mathbf{G}_{0}^{-1} \mathbf{G}_{1}, \boldsymbol{\xi}_{t}=\mathbf{G}_{0}^{-1} \mathbf{v}_{t}
$$

and

$$
\boldsymbol{\xi}_{t}=\mathbf{G}_{0}^{-1} \mathbf{v}_{t}=\left(\begin{array}{cc}
1 & 0 \\
\Upsilon_{0} & \left(\mathbf{I}_{k}-\mathbf{H}_{0}\right)^{-1}
\end{array}\right)\left(\begin{array}{c}
u_{t}^{o} \\
\mathbf{u}_{t}
\end{array}\right)=\left(\begin{array}{c}
u_{t}^{o} \\
\boldsymbol{\Upsilon}_{0} u_{t}^{o}+\left(\mathbf{I}_{k}-\mathbf{H}_{0}\right)^{-1} \mathbf{u}_{t}
\end{array}\right)
$$

\subsection{Structural impulse responses for country-specific oil supply shocks}

The reduced form solution, (23) can now be used in forecasting or for counterfactual analysis. The focus of our analysis is on the counterfactual effects of country-specific oil supply shocks. In particular, we are interested in the consequences of shocks to Iranian and Saudi Arabian oil supplies. To this end we consider the following 'structural' version of (23),

$$
\mathbf{Q z}_{t}=\mathbf{Q} \mathbf{a}_{t}+\mathbf{Q F} \mathbf{z}_{t-1}+\varepsilon_{t},
$$

where $\boldsymbol{\varepsilon}_{t}=\mathbf{Q} \boldsymbol{\xi}_{t}=\left(\varepsilon_{1 t}, \varepsilon_{2 t}, \ldots, \varepsilon_{k+1, t}\right)^{\prime}$ are the structural shocks, and $\mathbf{Q}$ is a $(k+1) \times(k+1)$ non-singular matrix. In a multi-country context due to spill-over effects across countries we need to allow for the possibility that some of the structural shocks might be correlated. To 
allow for non-zero correlations across the structural shocks we use the generalized impulse response function developed by Pesaran and Shin (1998). For model (24), the impulse response function of a unit shock to the $i^{\text {th }}$ structural error, $\varepsilon_{i t}$, is given by

$$
\mathbf{g}_{z}\left(h, \sigma_{i}\right)=E\left(\mathbf{z}_{t+h} \mid \mathbf{s}_{i}^{\prime} \varepsilon_{t}=\sigma_{i}, \mathfrak{I}_{t-1}\right)-E\left(\mathbf{z}_{t+h} \mid \mathfrak{I}_{t-1}\right), \text { for } h=0,1, \ldots
$$

where $\mathbf{s}_{i}$ is a $(k+1) \times 1$ vector of zeros with the exception of its $i^{\text {th }}$ element which is set to unity, $\sigma_{i}$ denotes the size of the shock, and $\mathfrak{I}_{t-1}=\left(\mathbf{z}_{t-1}, \mathbf{z}_{t-2}, \ldots\right)$. Using (24) we have (note that $\mathbf{a}_{t}$ is non-stochastic)

$$
\begin{aligned}
& \mathbf{g}_{z}\left(h, \sigma_{i}\right)=\mathbf{F}^{h} \mathbf{g}_{z}\left(h-1, \sigma_{i}\right), \text { for } h=1,2, \ldots, \\
& \mathbf{g}_{z}\left(0, \sigma_{i}\right)=\mathbf{Q}^{-1} E\left(\varepsilon_{t} \mid \mathbf{s}_{i}^{\prime} \varepsilon_{t}=\sigma_{i}, \mathfrak{I}_{t-1}\right)=\sigma_{i}^{-1} \mathbf{Q}^{-1} \boldsymbol{\Sigma}_{\varepsilon \varepsilon} \mathbf{s}_{i} .
\end{aligned}
$$

But $\boldsymbol{\Sigma}_{\varepsilon \varepsilon}=\mathbf{Q} \boldsymbol{\Sigma}_{\xi \xi} \mathbf{Q}^{\prime}$, where $\boldsymbol{\Sigma}_{\xi \xi}=E\left(\boldsymbol{\xi}_{t} \boldsymbol{\xi}_{t}^{\prime}\right)$ and can be identified from the reduced form of the GVAR-Oil model given by (23). Using this result we now have

$$
\mathbf{g}_{z}\left(0, \sigma_{i}\right)=\sigma_{i}^{-1} \boldsymbol{\Sigma}_{\xi \xi} \mathbf{Q}^{\prime} \mathbf{s}_{i}
$$

Therefore, to identify the effects of the structural shocks we need to identify $\mathbf{Q}^{\prime} \mathbf{s}_{i}$ which is the $i^{\text {th }}$ row of $\mathbf{Q}$. To identify all the structural shocks (and without imposing any restrictions on $\boldsymbol{\Sigma}_{\varepsilon \varepsilon}$ ) it is clear that we must set $\mathbf{Q}$ equal to an identity matrix. But if the aim is to identify the impulse response functions of some but not all of the structural shocks one needs only to focus on those rows of $\mathbf{Q}$ that relate to structural shocks of interest. In the present application where our focus is on country-specific oil supply shocks, we consider the following partitions of $\mathbf{Q}$ and $\varepsilon_{t}$

$$
\mathbf{Q}=\left(\begin{array}{ll}
\mathbf{Q}_{a a} & \mathbf{Q}_{a b} \\
\mathbf{Q}_{b a} & \mathbf{Q}_{b b}
\end{array}\right), \text { and } \varepsilon_{t}=\left(\begin{array}{c}
\varepsilon_{a t} \\
\varepsilon_{b t}
\end{array}\right)
$$

where $\varepsilon_{a t}=\left(p_{t}^{o}, q_{1 t}^{o}, q_{2 t}^{o}, \ldots, q_{N t}^{o}\right)^{\prime}$, with the rest of the structural shocks included in $\varepsilon_{b t}$. To identify the effects of $\boldsymbol{\varepsilon}_{a t}$ we assume that $\mathbf{Q}_{a b}=\mathbf{0}$, and

$$
\mathbf{Q}_{a a}=\left(\begin{array}{ccccc}
1 & 0 & \cdots & 0 & 0 \\
\gamma_{1}^{o} & 1 & \cdots & 0 & 0 \\
\vdots & \vdots & \ddots & \vdots & \vdots \\
\gamma_{N-1}^{o} & 0 & 0 & 1 & 0 \\
\gamma_{N}^{o} & 0 & 0 & 0 & 1
\end{array}\right)
$$


which is in line with the theoretical restrictions derived in Section 2. This specification allows oil price changes to contemporaneously affect country-specific oil supplies but not the reverse.

\section{Empirical application}

Before we can investigate the global macroeconomic consequences of country-specific oilsupply shocks, we need to estimate the GVAR-Oil model. We begin our empirical investigation with estimates of the oil price equation and discuss its robustness along several dimensions.

\subsection{Estimates of the oil price equation}

We include as many major oil producers as possible in our multi-country set up, subject to data availability, together with as many countries in the world to represent the global economy. The model includes 34 economies, which together cover more than $90 \%$ of world GDP. Out of these, ten are classified as "major oil producers", i.e. countries producing more than one percent of total world oil supply according to 2004-2013 averages (Table 1). The five major oil exporters, Canada, Iran, Mexico, Norway, and Saudi Arabia, clearly satisfy this condition, as does the UK, which remained a net oil exporter until 2006, and Indonesia, which was an OPEC member until January 2009. In addition, there are three other countries in our sample which produce significantly more than 2.4 million barrels per day (mbd): Brazil, China, and the U.S. (Table 2). Although net oil importers, these countries are the eleventh, fourth, and second largest oil producers in the world, respectively.

Unfortunately, we are not able to include Iraq (ranked fifth in the world in terms of proven oil reserves) in our sample due to lack of sufficiently long time series data for this country. This was also the case for Russia, the third largest oil producer in the world, for which quarterly observations are not available for the majority of our sample period although, as discussed below, we do consider the robustness of the estimates of the oil price equation to the inclusion of Russia, using a somewhat shorter period.

The ten major oil producers have one important feature in common, namely that the amount of oil they produce on any given day plays a significant role in the global oil markets, however, they differ considerably from each other in terms of how much oil they produce (and export), their level of proven oil reserves, as well as their spare capacity (Table 2). ${ }^{6}$ In

\footnotetext{
${ }^{6}$ Note that proven reserves at any given point in time are defined as "quantities of oil that geological and engineering information indicate with reasonable certainty can be recovered in the future from known reservoirs under existing economic and operating conditions" (British Petroleum Statistical Review of World
} 
Table 1: Countries and Regions in the GVAR Model

\begin{tabular}{lll}
\hline Major Oil Producers & \multicolumn{2}{c}{ Other Countries } \\
\cline { 3 - 3 } Net Exporters & & Aurope \\
Canada & Euro Area & Australia \\
Indonesia & Austria & India \\
Iran & Belgium & Japan \\
Mexico & Finland & Korea \\
Norway & France & Malaysia \\
Saudi Arabia & Germany & New Zealand \\
& Italy & Philippines \\
Net Importers & Netherlands & Singapore \\
Brazil & Spain & Thailand \\
China & Sweden & \\
United Kingdom & Switzerland & \\
United States & & Latin America \\
& Rest of the World & Argentina \\
& South Africa & Chile \\
& Turkey & Peru \\
\hline
\end{tabular}

Table 2: Oil Reserves, Production and Exports of Major Oil Producers, averages over 2004-2013

\begin{tabular}{|c|c|c|c|c|c|c|}
\hline \multirow[t]{2}{*}{ Country } & \multicolumn{2}{|c|}{ Oil Production } & \multicolumn{2}{|c|}{ Oil Exports } & \multicolumn{2}{|c|}{ Oil Reserves } \\
\hline & $\begin{array}{c}\text { Million } \\
\text { Barrels/day }\end{array}$ & $\begin{array}{l}\text { Percent } \\
\text { of World }\end{array}$ & $\begin{array}{c}\text { Million } \\
\text { Barrels/day }\end{array}$ & $\begin{array}{l}\text { Percent } \\
\text { of World }\end{array}$ & $\begin{array}{l}\text { Billion } \\
\text { Barrels }\end{array}$ & $\begin{array}{l}\text { Percent } \\
\text { of World }\end{array}$ \\
\hline \multicolumn{7}{|l|}{ Net Exporters } \\
\hline Canada & 3.5 & 4.0 & 1.5 & 3.7 & 177.0 & 11.7 \\
\hline Indonesia & 1.1 & 1.2 & 0.3 & 0.8 & 4.0 & 0.3 \\
\hline Iran & 4.0 & 4.7 & 2.4 & 5.8 & 144.1 & 9.5 \\
\hline Mexico & 3.3 & 3.8 & 1.6 & 4.0 & 12.3 & 0.8 \\
\hline Norway & 2.4 & 2.8 & 1.8 & 4.5 & 8.2 & 0.5 \\
\hline Saudi Arabia & 10.8 & 12.6 & 7.1 & 17.2 & 264.7 & 17.5 \\
\hline \multicolumn{7}{|l|}{ Net Importers } \\
\hline Brazil & 2.4 & 2.8 & - & - & 13.4 & 0.9 \\
\hline China & 4.1 & 4.7 & - & - & 16.5 & 1.1 \\
\hline United Kingdom & 1.5 & 1.7 & - & - & 3.3 & 0.2 \\
\hline United States & 9.5 & 11.0 & - & - & 34.2 & 2.3 \\
\hline World & 86.3 & 100.00 & 41.1 & 100.0 & 1510.3 & 100.00 \\
\hline
\end{tabular}

Source: Oil production data are from the U.S. Energy Information Administration International Energy Statistics, oil reserve data are from the British Petroleum Statistical Review of World Energy and oil export data are from the OPEC Annual Statistical Bulletin. 
particular, we note from Table 2 that although Iran has substantial reserves (4th largest in the world) its production is less than $5 \%$ of the world oil output, being similar to that of China (with only around $1 \%$ of the world's known reserves). What might be surprising is that Canada has in fact larger oil reserves than Iran but exports around 1 million barrels per day less than Iran.

Table 2 also shows that Saudi Arabia plays a key role when it comes to world oil supply. Not only does it produce more than $12.6 \%$ of world oil output and owns $17.5 \%$ of the world's proven oil reserves, it also exports around $17.2 \%$ of the world total, which is almost the same amount as the other four major oil exporters in our sample combined. Moreover, Saudi Arabia is not only the largest oil producer and exporter in the world, but it also has the largest spare capacity and as such is often seen as a "swing" producer. For example, following the Arab spring and the recent oil sanctions on Iran, Saudi Arabia has increased its production to stabilize the global oil markets. Therefore, one would expect that disruptions to global oil supplies would be compensated by an increase in Saudi Arabian oil production, whilst disruptions to Saudi Arabian oil supply could potentially only be partially compensated by other producers given that most of them are producing at (or near) capacity.

To take account of developments in the world economy, we include a measure of global output, $y_{t}$, in our oil price equation, computed as

$$
y_{t}=\sum_{i=1}^{N} w_{i} y_{i t}
$$

where $y_{i t}$ is the log of real GDP of country $i$ at time $t, i=1,2, \ldots N, w_{i}$ is the PPP GDP weight of country $i$, and $\sum_{j=0}^{N} w_{i}=1 .^{7}$ We compute $w_{i}$ as a three-year averages over 20072009 to reduce the impact of individual yearly movements on the weights. See Table 3 for the weights of each of the 26 countries and the euro area. Finally, to capture the global oil supply conditions, we include a measure of the log of world oil production, $q_{t}^{o}$, calculated as $q_{t}^{o}=\sum_{i=1}^{N} q_{i t}^{o}$, where $q_{i t}^{o}=0$ for the euro area and the 16 countries who are not major oil producers (see Table 1$){ }^{8}$

\footnotetext{
Energy), thus this measure could be uncertain.

${ }^{7}$ The PPP-GDP weights are computed using data from the World Bank World Development Indicator database. Data on real GDP, $y_{i t}$, over the period 1979Q2 to 2013Q1, for all countries but Iran, are obtained from Smith and Galesi (2014). GDP data for Iran over the period 1979Q1-2006Q4 are from Esfahani et al. (2014), which were updated using the International Monetary Fund's (IMF) International Financial Statistics and World Economic Outlook databases.

${ }^{8}$ Quarterly oil production series (in thousand barrels per day) were obtained from the U.S. Energy Information Administration International Energy Statistics. But these data are only available from 1994Q1, so quarterly series from 1979Q2 to 1993Q4 were linearly interpolated (backward) using annual series. For a description of the interpolation procedure used see Section 1.1 of Supplement A of Dees et al. (2007).
} 
Table 3: PPP-GDP Weights (in percent), averages over 2007-2009

\begin{tabular}{lclclc}
\hline Country & $\begin{array}{c}\text { PPP GDP } \\
\text { Weights }\left(w_{i}\right)\end{array}$ & Country & $\begin{array}{c}\text { PPP GDP } \\
\text { Weights }\left(w_{i}\right)\end{array}$ & Country & $\begin{array}{c}\text { PPP GDP } \\
\text { Weights }\left(w_{i}\right)\end{array}$ \\
\hline Argentina & 0.99 & Iran & 1.43 & South Africa & 0.88 \\
Australia & 1.42 & Japan & 7.47 & Saudi Arabia & 1.02 \\
Brazil & 3.44 & Korea & 2.28 & Singapore & 0.44 \\
Canada & 2.25 & Malaysia & 0.67 & Sweden & 0.62 \\
China & 14.49 & Mexico & 2.75 & Switzerland & 0.60 \\
Chile & 0.42 & Norway & 0.48 & Thailand & 0.95 \\
Euro Area & 17.86 & New Zealand & 0.22 & Turkey & 1.79 \\
India & 6.15 & Peru & 0.42 & UK & 3.87 \\
Indonesia & 1.60 & Philippines & 0.55 & USA & 24.93 \\
& & & & & \\
\hline
\end{tabular}

Notes: The euro area block includes 8 of the 11 countries that initially joined the euro on January 1, 1999: Austria, Belgium, Finland, France, Germany, Italy, Netherlands, and Spain. Source: World Bank World Development Indicators, 2007-2009.

For empirical application we use the nominal price of oil in U.S. dollars. The advantage of the nominal oil price is that its movement reflects political factors more prominently than real oil prices. These political factors could be quite important in our application given that our focus is on the consequences of country-specific oil supply shocks, potentially due to oil sanctions or wars. In addition, in terms of the country-specific VARX* models (see Section 4.2) the inclusion of the nominal price seems more appropriate as the real exchange rate is already included in the model, and combining the two variables can have the same effect as real oil prices in domestic currency. To check the robustness of our results to the choice of the oil price variable, we also estimated the oil price equation as well as the GVAR-Oil model as whole using real oil prices (with U.S. CPI used as the deflator) and found the results to be quite similar. This is perhaps not surprising since nominal oil prices are much more volatile than U.S. CPI. Given that we find that it does not make much difference whether one uses nominal or real oil prices, and the fact that geopolitical factors are better captured using nominal prices, all the estimates reported below are obtained using the nominal price of oil. ${ }^{9}$

Having constructed the series for $q_{t}^{o}$ and $y_{t}$, we estimated the oil price equation using the following ARDL specification

$$
p_{t}^{o}=c_{p}+\sum_{\ell=1}^{m_{p^{o}}} \phi_{\ell} p_{t-\ell}^{o}+\sum_{\ell=1}^{m_{y}} \alpha_{\ell} y_{t-\ell}+\sum_{\ell=1}^{m_{q^{o}}} \beta_{\ell} q_{t-\ell}^{o}+u_{t}^{o}
$$

where the lag orders, $m_{p^{o}}, m_{y}$ and $m_{q^{o}}$ are allowed to differ across the variables and selected

\footnotetext{
${ }^{9}$ The results based on real oil prices are available upon request.
} 
using, for instance, the Akaike Information Criterion (AIC). It is also easily seen that

$$
\frac{\epsilon_{y}}{\epsilon_{p^{o}}}=\left(1-\sum_{\ell=1}^{m_{p^{o}}} \phi_{\ell}\right)^{-1} \sum_{\ell=1}^{m_{y}} \alpha_{\ell}, \text { and } \frac{1}{\epsilon_{p^{o}}}=-\left(1-\sum_{\ell=1}^{m_{p^{o}}} \phi_{\ell}\right)^{-1} \sum_{\ell=1}^{m_{q^{o}}} \beta_{\ell}
$$

and hence we are able to estimate long-run price and income elasticities of the global oil demand equation as

$$
\epsilon_{p^{o}}=-\left(\sum_{\ell=1}^{m_{q^{o}}} \beta_{\ell}\right)^{-1}\left(1-\sum_{\ell=1}^{m_{p^{o}}} \phi_{\ell}\right), \text { and } \epsilon_{y}=-\left(\sum_{\ell=1}^{m_{q^{o}}} \beta_{\ell}\right)^{-1} \sum_{\ell=1}^{m_{y}} \alpha_{\ell} .
$$

We select the lag order of the ARDL model using the AIC, subject to a maximum of four lags on each of the variables, $m_{p^{o}}^{\max }=m_{y}^{\max }=m_{q^{o}}^{\max }=4$. Allowing the lag order selection to differ across the variables, the AIC selects the lag orders $(4,1,1)$. We obtained the same outcome using the Schwarz Bayesian Criterion. Table 4 presents the ARDL estimates of equation (28), from which we can see that all coefficients have the right signs and are statistically significant at the $1 \%$ level (except for the coefficient of $p_{t-4}^{o}$ which is statistically significant at the $5 \%$ level). Moreover, testing for the existence of a level (or long-run) relationship between $p_{t}^{o}, y_{t}$ and $q_{t}^{o}$, we obtained an $F$-statistic of 5.01 which is above the $95 \%$ upper bound critical value of the test at 4.95. ${ }^{10}$ We therefore reject the null hypothesis of no level effects amongst the three variables. Furthermore, we obtain an $\bar{R}^{2}=0.21$ for the error-correction representation of the ARDL model, which is a reasonable fit of the errorcorrecting equation given the generally held view that oil prices tend to follow random walk (under which we would have expected $\bar{R}^{2}$ to be around zero).

To obtain the estimates of the long-run price $\left(\widehat{\epsilon}_{p^{o}}\right)$ and income elasticity $\left(\widehat{\epsilon}_{y}\right)$ of demand, we use the OLS estimates of the short-run coefficients $(\widehat{\phi}, \widehat{\alpha}$, and $\widehat{\beta})$ in equation (28) and calculate the elasticities based on equation (29). Our results suggest a price elasticity of -0.212 (Table 4), which falls in the range of the estimates obtained in the literature. For instance, Pesaran et al. (1998) find an elasticity of between 0.0 to -0.48 for Asian countries, Gately and Huntington (2002) report elasticities between -0.12 to -0.64 for both OECD and non-OECD countries, Krichene (2006) obtains estimates of between -0.03 to -0.08 for various countries, and Kilian and Murphy (2014) report an elasticity of -0.26 . Moreover, although our estimate for the income elasticity of demand (0.727) is lower than that reported in Pesaran et al. (1998) for Asian developing countries $(1.0-1.2)$, it is in line with the estimates of between 0.53 to 0.95 and 0.54 to 0.90 in Gately and Huntington (2002)

\footnotetext{
${ }^{10}$ For a discussion of the bound testing approach see Pesaran et al. (2001).
} 


\section{Table 4: Estimates of the Oil Price Equation}

\begin{tabular}{lccc}
\hline Countries & 34 Countries & 34 Countries & $\begin{array}{c}\text { 35 Countries } \\
\text { including Russia }\end{array}$ \\
Estimation Period & 1980q2-2013q1 & 1994q2-2013q1 & $1994 \mathrm{q} 2-2013 \mathrm{q} 1$ \\
\hline
\end{tabular}

(a) ARDL Estimates

$\begin{array}{cccc}\widehat{\phi}_{1} & 1.185^{* *} & 1.172^{* *} & 1.187^{* *} \\ & (0.088) & (0.117) & (0.118) \\ \widehat{\phi}_{2} & -0.631^{* *} & -0.711^{* *} & -0.717^{* *} \\ & (0.132) & (0.176) & (0.178) \\ \widehat{\phi}_{3} & 0.460^{* *} & 0.450^{*} & 0.446^{*} \\ & (0.131) & (0.176) & (0.178) \\ \widehat{\phi}_{4} & -0.199^{*} & -0.275^{*} & -0.258^{*} \\ & (0.087) & (0.114) & (0.115) \\ \widehat{\alpha}_{1} & 0.635^{* *} & 1.189^{* *} & 1.207^{* *} \\ & (0.178) & (0.286) & (0.314) \\ \widehat{\beta}_{1} & -0.873^{* *} & -1.394^{*} & -1.144^{*} \\ & (0.280) & (0.548) & (0.576)\end{array}$

(b) Long-run income $\left(\widehat{\epsilon}_{y}\right)$ and price $\left(\widehat{\epsilon}_{p^{o}}\right)$ elasticities

$\begin{array}{cccc}\widehat{\epsilon}_{y} & 0.727^{* *} & 0.853^{* *} & 1.055^{*} \\ & (0.055) & (0.274) & (0.414) \\ & & & \\ \widehat{\epsilon}_{p^{\circ}} & -0.212^{* *} & -0.262^{* *} & -0.300^{*} \\ & (0.031) & (0.085) & (0.130)\end{array}$

(c) Testing for the existence of level relationship amongst $p_{t}^{o}, y_{t}$ and $q_{t}^{o}$

$\begin{array}{llll}F \text {-statistic } & 5.01 & 5.45 & 4.72 \\ 95 \% \text { Upper Bound } & 4.95 & 5.00 & 5.00 \\ 90 \% \text { Upper Bound } & 4.19 & 4.23 & 4.23\end{array}$

Notes: The dependant variable is $p_{t}^{o}$. The estimates are based on an ARDL $(4,1,1)$ model. An intercept is included in all regressions. Standard errors are presented below the corresponding coefficients in brackets. Symbols $* *$ and $*$ denote significance at $1 \%$ and $5 \%$ respectively. See Table 1 for the 34 countries included in our model. 
and Krichene (2006), respectively. ${ }^{11}$ Furthermore, in a recent study, Mohaddes (2013), using annual data between 1965 and 2009 for 65 major oil consumers, estimates dynamic heterogeneous panel data models with interactive effects and finds a price elasticity of -0.15 and an income elasticity of 0.68 , which are close to the elasticities reported in Table 4.

As explained earlier we do not include Russia in our sample due to lack of sufficiently long time series data on macro variables such as real GDP, inflation, and the exchange rate. Having data over a sufficiently long time period is important when it comes to estimating the GVAR-Oil model, and including Russia would have meant estimating the country-specific VARX* models using 76 quarterly observations rather than 132, making the results much less reliable. However, given that Russia is the third largest oil producer in the world (after Saudi Arabia and the U.S.) we thought it important to make sure that the oil price equation estimates in column 2 of Table 4 are not substantially different were we to include Russia in our sample. To this end we used quarterly GDP data for Russia from 1993Q1 to $2013 \mathrm{Q} 1$ from the IMF International Financial Statistics and updated the PPP GDP weights using the World Bank World Development Indicator database so as to calculate world income $\left(y_{t}\right)$ inclusive of Russia. We also included Russian oil production in the global oil supply variable $\left(q_{t}^{o}\right)$, using quarterly Russian oil production series from the U.S. Energy Information Administration International Energy Statistics.

The ARDL estimates of the oil price equation with Russia included (35 countries) are reported in the last column of Table 4, from which we observe that the estimates of the shortrun coefficients $(\widehat{\phi}, \widehat{\alpha}$, and $\widehat{\beta})$ are all statistically significant and that, as before, we cannot reject the existence of a level (or long-run) relationship relating oil prices to oil supplies and world real income, although the significance is now at the lower level of $90 \%$. We notice that the long-run price and income elasticities of demand, although still in line with that of the literature, are larger than the estimates based on a substantially longer sample period (56 more observations) but excluding Russia (column 2), however, the standard errors of the estimates are quite a bit larger. To compare the estimates with and without Russia but using the same sample period we re-estimate the oil price equation for the original 34 countries but using data over the shorter period 1994Q2-2013Q1. These results are reported under column 3 of Table 4, and show that (i) the elasticities of demand and their standard errors are somewhat larger when the sample period is shorter and (ii) the elasticities and their standard errors are smaller when Russia is not included in the sample. Overall, it seems that the inclusion of Russia, while increasing the estimated long-run elasticities of demand, yields substantially larger standard errors (compare columns 3 and 4 of Table 4). The larger

\footnotetext{
${ }^{11}$ See also Fattouh (2007) for an extensive survey of the literature on income and price elasticities of demand for energy.
} 
price and income elasticities obtained when Russia is included must therefore be balanced by the fact that the estimates are much less precisely estimated and have a greater margin of errors as compared to the elasticity estimates obtained using the longer sample period excluding Russia. We, therefore, feel justified in proceeding with the longer sample period even though this means that Russia must be excluded from our analysis.

\subsection{Estimates of the country-specific VARX* models}

While our analysis covers 34 countries, in the construction of the GVAR-Oil model we create a block comprising 8 of the 11 countries that initially joined the euro area on January 1, 1999, namely Austria, Belgium, Finland, France, Germany, Italy, Netherlands, and Spain. The time series data for the euro area are constructed as cross-sectionally weighted averages of the variables of the eight euro area countries, using Purchasing Power Parity GDP weights, averaged over the 2007-2009 period (see Table 3). Thus, as displayed in Table 1, the GVAROil model includes one region and 26 country-specific VARX* models. For various data sources used to build the quarterly GVAR-Oil dataset, covering 1979Q2 to 2013Q1, and for the construction of the variables see Appendix A. For brevity, we provide evidence for the weak exogeneity assumption of the foreign variables and discuss the issue of structural breaks in the context of our GVAR-Oil model in Appendix B.

\subsubsection{Specification of the country-specific VARX* models}

In our application each country-specific model has a maximum of six endogenous variables. Using the same terminology as in equation (20), the $k_{i} \times 1$ vector of country-specific endogenous variables is defined as $\mathbf{x}_{i t}=\left(q_{i t}^{o}, y_{i t}, \pi_{i t}, e p_{i t}, r_{i t}^{S}, r_{i t}^{L},\right)^{\prime}$, where $q_{i t}^{o}$ is the $\log$ of oil production at time $t$ for country $i, y_{i t}$ is the log of real Gross Domestic Product, $\pi_{i t}$ is the rate of inflation, $e p_{i t}$ is the log deflated exchange rate, and $r_{i t}^{S}\left(r_{i t}^{L}\right)$ is the short (long) term interest rate, if country $i$ is a major oil producer, otherwise $\mathbf{x}_{i t}=\left(y_{i t}, \pi_{i t}, e p_{i t}, r_{i t}^{S}, r_{i t}^{L},\right)^{\prime} .{ }^{12}$ The model for the U.S. differs from the rest in two respects: given the importance of U.S. financial variables in the global economy, the log of world real equity prices, $e q_{t}$ is included in the U.S. model as an endogenous variable, and as weakly exogenous in the other country models $\left(e q_{i t}^{*}=e q_{t}\right)$, whilst U.S. dollar exchange rates are included as endogenous variables in all models except for the United States. ${ }^{13}$ The endogenous variables of the U.S. model

\footnotetext{
${ }^{12}$ Note that long term interests are not available for all countries, and short term and long term interest rates are not available in the case of Iran and Saudi Arabia.

${ }^{13}$ Note that the inclusion of the equity price variable in the U.S. model is supported by empirical evidence that shows that there is a global financial cycle in capital flows, asset prices, and credit growth, and that cycle is mainly driven by monetary policy settings of the United States, affecting leverage of international banks, and cross-border capital/credit flows. See, for instance, Rey (2013).
} 
are therefore given by $\mathbf{x}_{U S, t}=\left(e q_{t}, q_{U S, t}^{o}, y_{U S, t}, \pi_{U S, t}, r_{U S, t}^{S}, r_{U S, t}^{L}\right)^{\prime}$.

In the case of all countries, except for the U.S. and euro area, the foreign variables included in the country-specific models, computed as in equation (21), are given by $\mathbf{x}_{i t}^{*}=$ $\left(e q_{i t}^{*}, y_{i t}^{*}, \pi_{i t}^{*}, e p_{i t}^{*}, r_{i t}^{* S}, r_{i t}^{* L}\right)^{\prime}$. The trade weights are computed as three-year averages over $2007-2009 .{ }^{14}$

Table 5: Variables Specification of the Country-specific VARX* Models

\begin{tabular}{|c|c|c|c|c|c|}
\hline \multicolumn{2}{|c|}{ The U.S. Model } & \multicolumn{2}{|c|}{$\begin{array}{c}\text { Oil Producers } \\
\text { (except U.S.) }\end{array}$} & \multicolumn{2}{|c|}{$\begin{array}{c}\text { Remaining } 17 \\
\text { VARX* Models }\end{array}$} \\
\hline Domestic & Foreign & Domestic & Foreign & Domestic & Foreign \\
\hline$y_{i t}$ & $y_{i t}^{*}$ & $y_{i t}$ & $y_{i t}^{*}$ & $y_{i t}$ & $y_{i t}^{*}$ \\
\hline$\pi_{i t}$ & - & $\pi_{i t}$ & $\pi_{i t}^{*}$ & $\pi_{i t}$ & $\pi_{i t}^{*}$ \\
\hline- & $e p_{i t}^{*}$ & $e p_{i t}$ & - & $e p_{i t}$ & - \\
\hline$r_{i t}^{S}$ & - & $r_{i t}^{S}$ & $r_{i t}^{* S}$ & $r_{i t}^{S}$ & $r_{i t}^{* S}$ \\
\hline$r_{i t}^{L L}$ & - & $r_{i t}^{L t}$ & $r_{i t}^{* t}$ & $r_{i t}^{L t}$ & $r_{i t}^{* t}$ \\
\hline$q_{i t, s}^{o}$ & - & $q_{i t, s}^{o}$ & - & - & - \\
\hline$e q_{t}$ & - & - & $e q_{t}$ & - & $e q_{t}$ \\
\hline- & $p_{t}^{o}$ & - & $p_{t}^{o}$ & - & $p_{t}^{o}$ \\
\hline
\end{tabular}

We excluded the foreign inflation variable, $\pi_{E A, t}^{*}$, from the euro model since, based on some preliminary tests, we could not maintain that $\pi_{E A, t}^{*}$ is weakly exogenous. Also, given the pivotal role played by the U.S. in global financial markets, we excluded the foreign interest rates, $r_{U S, t}^{* S}$ and $r_{U S, t}^{* L}$, from the U.S. model. The exclusion of these variables from the U.S. model was also supported by preliminary test results showing that $r_{U S, t}^{* S}$ and $r_{U S, t}^{* L}$ can not be assumed to be weakly exogenous when included in the U.S. model. A similar result was found when the foreign inflation variable, $\pi_{U S, t}^{*}$, was included in the U.S. model. In short, the U.S. model includes only two foreign variables, namely $\mathbf{x}_{U S, t}^{*}=\left(y_{U S, t}^{*}, e p_{U S, t}^{*}\right)^{\prime}$, where $e p_{U S, t}^{*}=\sum_{j=1}^{N} w_{U S A, j}\left(e_{j t}-p_{j t}\right), w_{U S A, j}$ is the share of U.S. trade with country $j, e_{j t}$ is the log of US dollar exchange rate with respect to the currency of country $j$, and $p_{j t}$ is the $\log$ CPI price index of country $j$. The three different sets of individual country-specific models are summarized in Table 5 .

\subsubsection{Lag order selection, cointegrating relations, and persistence profiles}

We use quarterly observations over the period 1979Q2-2013Q1, across the different specifications in Table 5, to estimate the 27 country-specific $\operatorname{VARX} *\left(s_{i}, s_{i}^{*}\right)$ models separately.

\footnotetext{
${ }^{14} \mathrm{~A}$ similar approach has also been followed in the case of Global VAR models estimated in the literature. See, for example, Dees et al. (2007) and Cashin et al. (2015).
} 
We select the lag orders of the domestic and foreign variables, $s_{i}$ and $s_{i}^{*}$, by the Akaike Information Criterion (AIC) applied to the underlying unrestricted VARX* models, with the maximum lag orders set to 2 , in view of the limited number of time series observations available. The selected lag orders are reported in Table 6.

Table 6: Lag Orders of the Country-specific VARX*(s, s*) Models together with the Number of Cointegrating Relations (r)

\begin{tabular}{|c|c|c|c|c|c|c|c|}
\hline \multirow[b]{2}{*}{ Country } & \multicolumn{2}{|c|}{ VARX* Order } & \multirow{2}{*}{$\begin{array}{c}\text { Cointegrating } \\
\text { relations }\left(\hat{r}_{i}\right)\end{array}$} & \multirow[b]{2}{*}{ Country } & \multicolumn{2}{|c|}{ VARX* Order } & \multirow{2}{*}{$\begin{array}{l}\text { Cointegrating } \\
\text { relations }\left(\hat{r}_{i}\right)\end{array}$} \\
\hline & $\hat{s}_{i}$ & $\hat{s}_{i}^{*}$ & & & $\hat{s}_{i}$ & $\hat{s}_{i}^{*}$ & \\
\hline Argentina & 2 & 2 & 2 & Norway & 2 & 1 & 2 \\
\hline Australia & 1 & 1 & 2 & New Zealand & 2 & 2 & 2 \\
\hline Brazil & 1 & 2 & 2 & Peru & 2 & 2 & 2 \\
\hline Canada & 1 & 2 & 3 & Philippines & 2 & 1 & 2 \\
\hline China & 2 & 1 & 2 & South Africa & 2 & 1 & 1 \\
\hline Chile & 2 & 1 & 2 & Saudi Arabia & 2 & 1 & 1 \\
\hline Euro Area & 2 & 1 & 2 & Singapore & 1 & 1 & 2 \\
\hline India & 2 & 2 & 1 & Sweden & 2 & 1 & 2 \\
\hline Indonesia & 2 & 1 & 3 & Switzerland & 2 & 1 & 2 \\
\hline Iran & 2 & 1 & 1 & Thailand & 2 & 1 & 2 \\
\hline Japan & 2 & 2 & 3 & Turkey & 2 & 2 & 1 \\
\hline Korea & 2 & 2 & 4 & UK & 1 & 1 & 2 \\
\hline Malaysia & 1 & 1 & 1 & USA & 2 & 1 & 3 \\
\hline Mexico & 1 & 2 & 3 & & & & \\
\hline
\end{tabular}

Notes: $\hat{s}_{i}$ and $\hat{s}_{i}^{*}$ denote the estimated lag orders for the domestic and foreign variables, respectively, selected by the Akaike Information Criterion, with the maximum lag orders set to 2 . The number of cointegrating relations $\left(\hat{r}_{i}\right)$ are selected using the trace test statistics based on the $95 \%$ critical values from MacKinnon (1991) for all countries except for Norway, South Africa, Saudi Arabia, and the UK, for which we reduced $r_{i}$ below that suggested by the trace statistic to ensure the stability of the global model.

Having established the lag orders, we proceed to determine the number of long-run relations. Cointegration tests with the null hypothesis of no cointegration, one cointegrating relation, and so on are carried out using Johansen's maximal eigenvalue and trace statistics as developed in Pesaran et al. (2000) for models with weakly exogenous $I$ (1) regressors, unrestricted intercepts and restricted trend coefficients. We choose the number of cointegrating relations $\left(r_{i}\right)$ based on the trace test statistics, given that it has better small sample properties than the maximal eigenvalue test, using the $95 \%$ critical values from MacKinnon (1991).

It is now important to investigate the dynamic properties of the GVAR-Oil model when the 27 individual country models are combined with the oil price equation. In the GVAR literature this is done by examining the persistence profiles (PPs) of the effects of system wide shocks developed in Lee and Pesaran (1993) and Pesaran and Shin (1996). On impact 
Figure 1: Persistence Profiles of the Effect of a System-wide Shock to the Cointegrating Relations

(a) All Countries

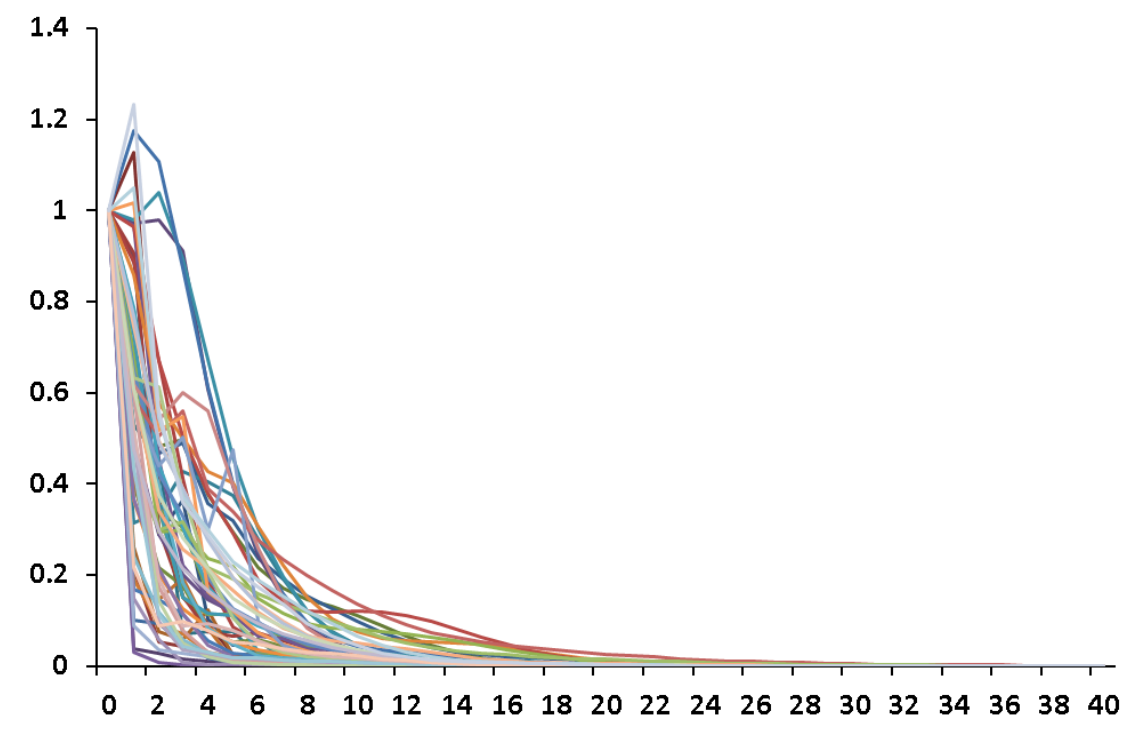

(b) Iran

(c) Saudi Arabia
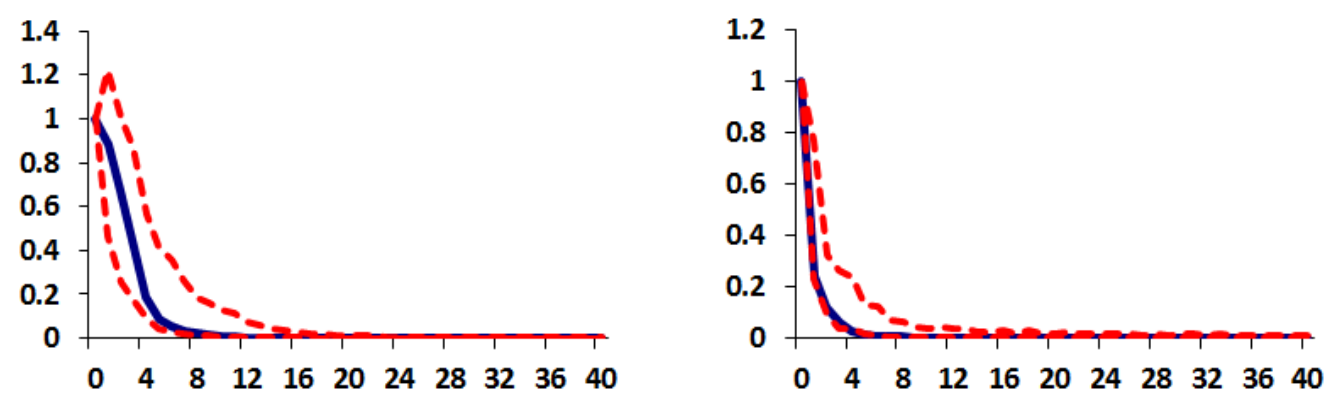

Notes: Figures show median effects of a system-wide shock to the cointegrating relations with $95 \%$ bootstrapped confidence bounds for Iran and Saudi Arabia. 
the PPs are normalized to take the value of unity, but the rate at which they tend to zero provides information on the speed with which equilibrium correction takes place in response to shocks. The PPs could initially over-shoot, thus exceeding unity, but must eventually tend to zero if the relationship under consideration is indeed cointegrated. In our preliminary analysis of the PPs for the full GVAR-Oil model we notice that, in the case of a few of the countries, the speed of convergence was rather slow. In particular, the speed of adjustment was very slow for Norway, South Africa, Saudi Arabia, and the UK. This may be due to the fact that the number of cointegrating relations are estimated at the level of individual countries (conditional on the foreign variables), whilst the PPs are computed using the GVAR-Oil model as a whole, which tends to have fewer cointegrating relations as compared to the number of cointegrating relations identified at the individual country levels. To address this issue we reduced the number of cointegrating relations for these economies, and ended up with 55 cointegrating relations as reported in Table 6 . The associated persistence profiles are shown in Figure 1a, from which we see that the profiles overshoot for six of the 55 cointegrating vectors before quickly tending to zero. The half-life of the shocks is generally less than 5 quarters and speed of convergence is relatively fast. Focusing on the persistence profiles for Iran and Saudi Arabia we plot these PPs together with their $95 \%$ bootstrapped error bands in Figures 1b and 1c. For these two major oil exporters we notice that the speed of convergence is very fast, which is in line with those reported for oil exporters in the literature. See Esfahani et al. (2013) and Esfahani et al. (2014) who also argue that the faster speeds of adjustment towards equilibrium experienced by some of the major oil exporters could be due to the relatively underdeveloped nature of money and capital markets in these economies.

\section{Counterfactual analysis of oil supply shocks}

With the GVAR-Oil model fully specified and shown to have a number of desirable statistical properties, see the detailed discussion above and in Appendix B, we can now consider the effects of country-specific supply disruptions. As illustrated in Section 2, the disaggregated nature of the model allows us to identify country-specific oil supply shocks and answer counterfactual questions regarding the possible macroeconomic effects of oil supply disruptions on the global economy. Our proposed scheme for identification of country-specific supply shocks is based on the assumption that changes in individual country oil production are unimportant relative to changes in the world oil supplies, and as a result the correlation of oil prices and country-specific oil supply shocks tend to zero for sufficiently large number of oil producers. Although we show that such an identification procedure is applicable even if 
the country-specific oil supply shocks are weakly correlated, in the sense defined by Chudik et al. (2011). Our approach to identification of oil supply shocks differ from the literature which considers identification of global supply shocks, rather than shocks originating from a specific country or a region, typically by imposing sign restrictions on the structural parameters of a three equation VAR model in oil prices, world real output, and global oil production (see, for instance, Kilian and Murphy 2012, Baumeister and Peersman 2013b, and Cashin et al. 2014).

Dealing with country-specific shocks raises a new issue which is absent from the global oil supply and demand analysis; namely, we need to make some assumptions about the likely contemporaneous responses of other oil producers to the shock. Different counterfactual scenarios for such responses can be considered. One possibility would be to assume zero contemporaneous supply responses, and allow the effects of the shock to work through oil price changes and secondary lagged feedback effects. Alternatively, one can use historically estimated covariances of the oil supply shocks. To allow for the possible cross-country oil supply spillover effects we make use of the structural generalized impulse response functions based on historically estimated covariances of the country-specific oil supply shocks. See the theoretical analysis of Section 3.1, and the generalized impulse response functions given by (25) and (26).

\subsection{An adverse shock to Iranian oil supply}

We first consider the oil price and production effects of a negative unit shock (equal to one-standard-error) to Iranian oil supply. The associated structural impulse responses together with their $95 \%$ error bands are given in Figure 2. This figure clearly shows that, following the supply shock, Iranian production temporarily falls by around $16 \%$ in the first four quarters (equivalent to $0.64 \mathrm{mbd}$ ), and the output effects remain statistically significant for six quarters. Reacting to the loss in Iran's oil output and to stabilize the oil markets, other OPEC producers (Indonesia and Saudi Arabia in particular) increase their production. Saudi Arabian production initially increases by $8 \%$ and eventually by $13 \%$ per annum in the long run. As a result, oil prices rise by $2 \%$ (being statistically significant in the first fourth quarters), but in the long run they fall back by $5.4 \%$ per annum. The fall in oil prices in the long run is due to the persistent nature of oil output from Saudi Arabia, with the rise in Saudi oil production being maintained at a higher level following the shock. As far as supply responses by other oil producers, we cannot find any statistically significant impact arising from the adverse shock to Iran's oil supply.

The evolution of Iranian and Saudi Arabian oil production (in mbd) over the 1978-2013 
Figure 2: Structural Impulse Responses of a Negative Unit Shock to Iranian Oil Supply
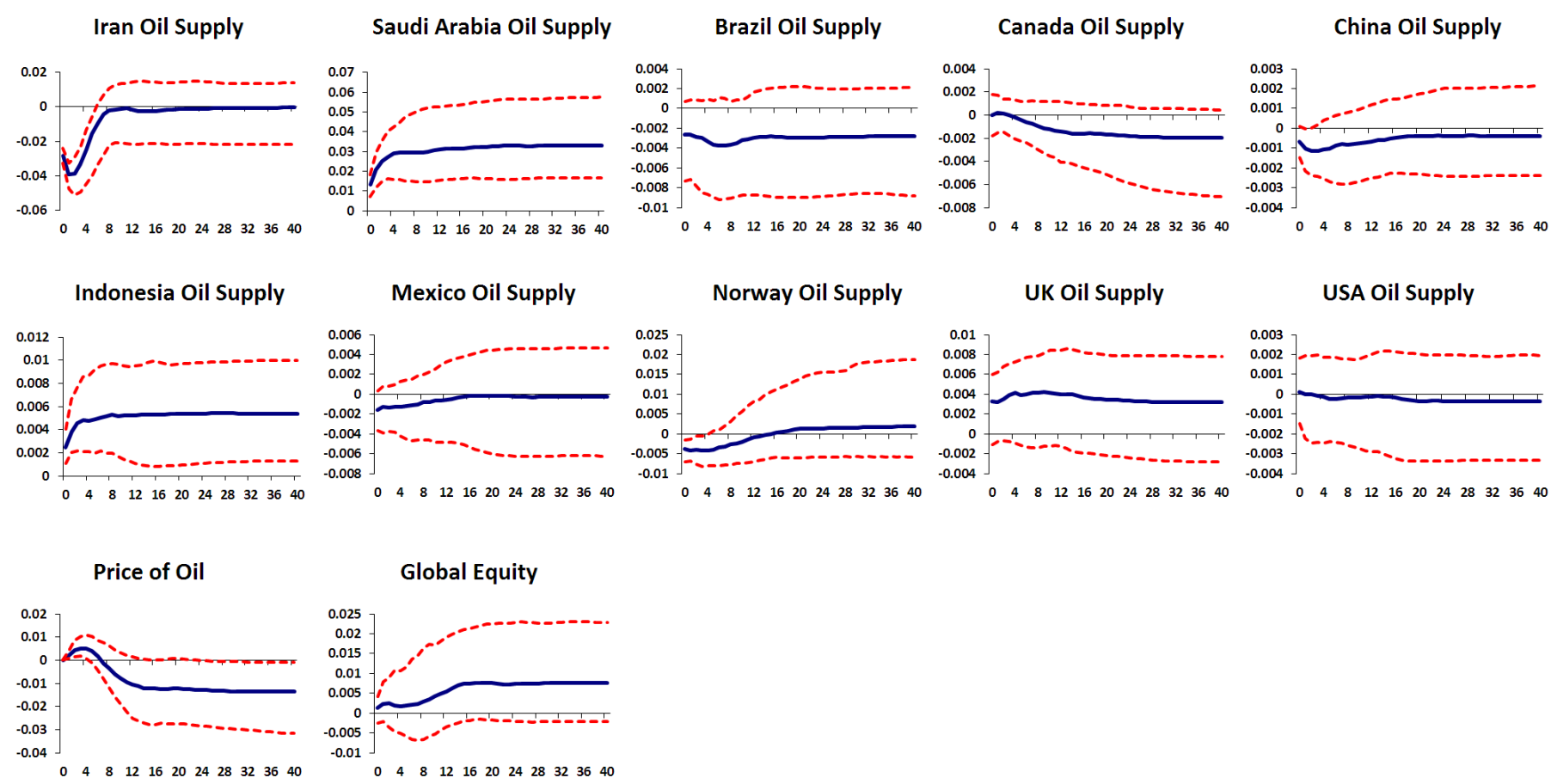

Notes: Figures show median impulse responses to a one-standard-deviation decrease in Iranian oil supply, with 95 percent bootstrapped confidence bounds. The horizon is quarterly.

Figure 3: Iranian and Saudi Arabian Oil Production in Million Barrels per Day, 1978-2013

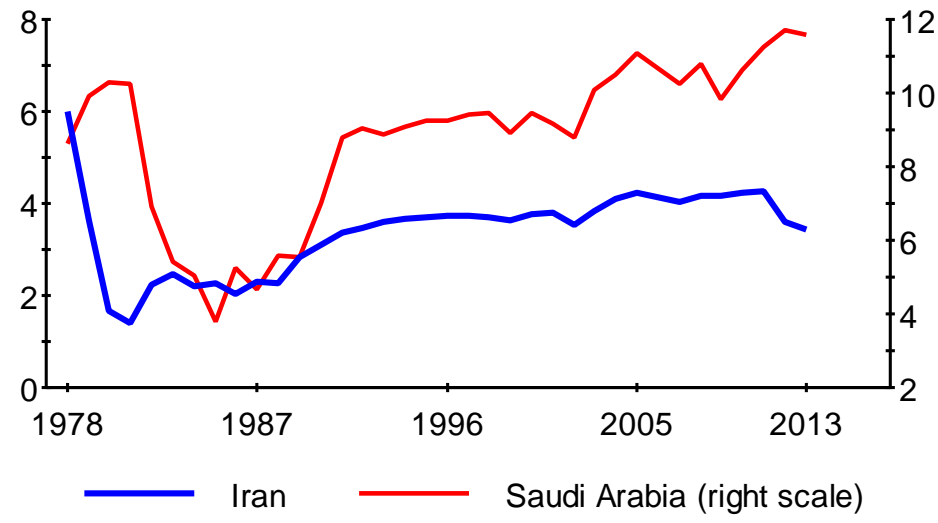

Source: U.S. Energy Information Administration International Energy Statistics. 


\section{Figure 4: Structural Impulse Responses of a Negative Unit Shock to Iranian Oil Supply}
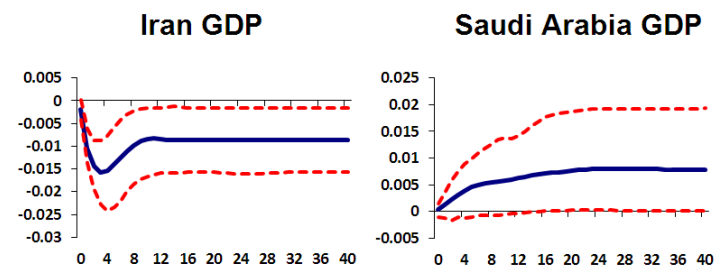

Canada GDP

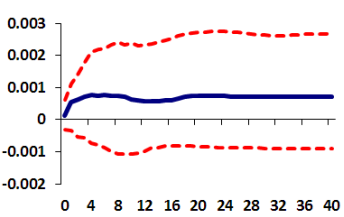

Indonesia GDP

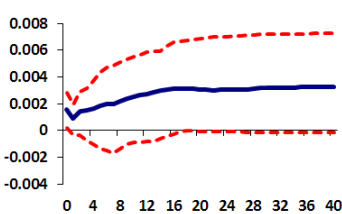

0

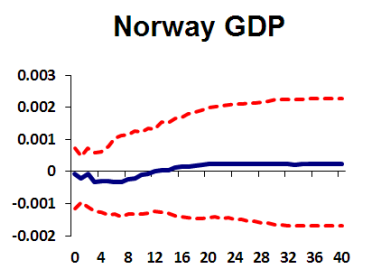

Singapore GDP

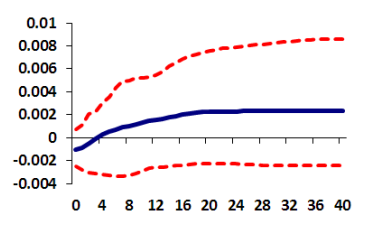

UK GDP

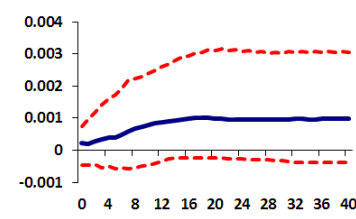

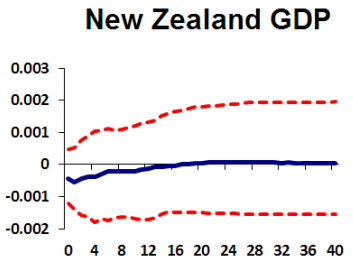

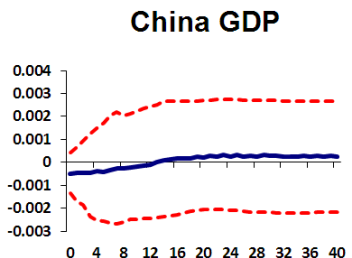

Japan GDP

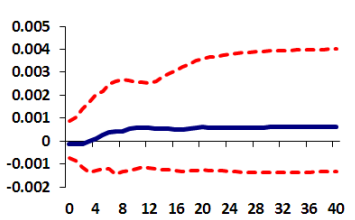

New Zealand GDP

Sweden GDP

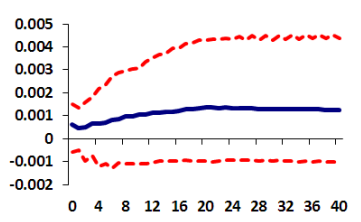

USA GDP

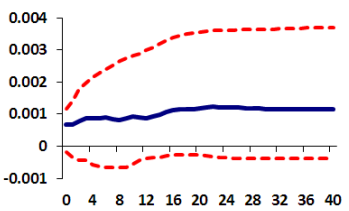

Argentina GDP

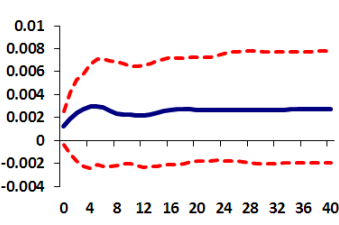

Chile GDP

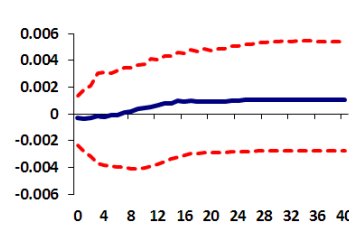

Korea GDP

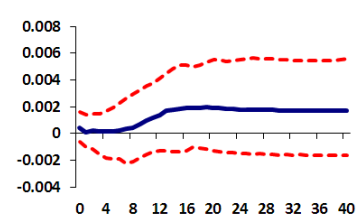

Peru GDP

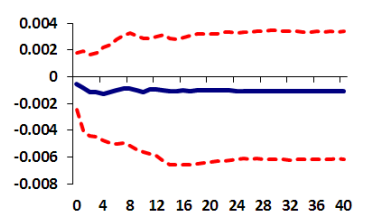

Switzerland GDP

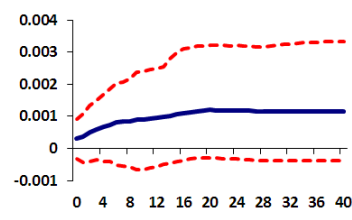

Australia GDP

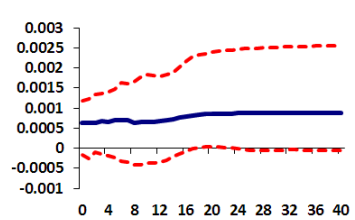

Euro Area GDP

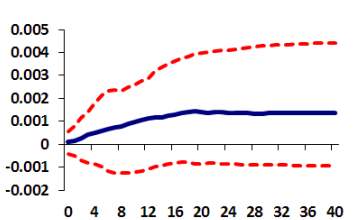

Malaysia GDP

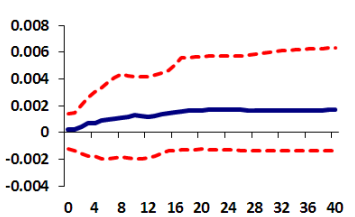

Philippines GDP

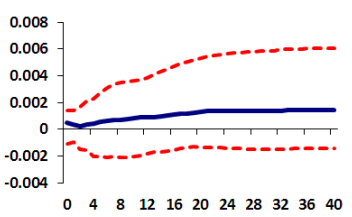

Thailand GDP

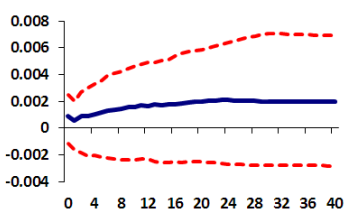

Brazil GDP

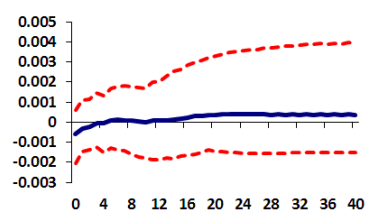

India GDP

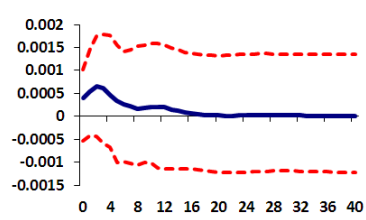

Mexico GDP

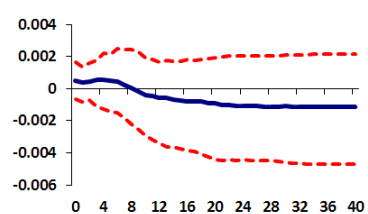

South Africa GDP

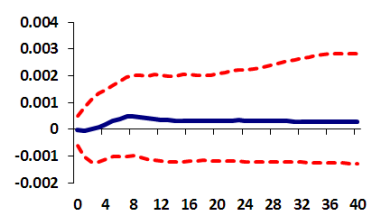

Turkey GDP

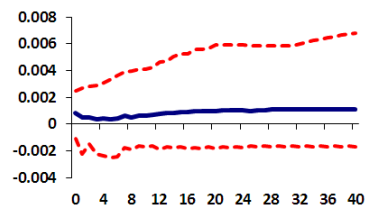

Notes: Figures show median impulse responses to a one-standard-deviation decrease in Iranian oil supply, with 95 percent bootstrapped confidence bounds. The horizon is quarterly. 
period is displayed in Figure 3, and clearly shows two distinct periods of large reduction in Iranian oil output: the first one coincides with the Iranian revolution and its aftermath, namely the period 1978/79-1981, and the second one starts mid-2011 and coincides with the intensification of sanctions against Iran. In the first period, although the revolutionary upheavals and the strikes by oil workers halted Iranian oil production in 1978/79, it was a conscious decision by the Provisional Iranian Government to reduce the level of oil production to around 30 percent below its average level over the 1971-78 period (Mohaddes and Pesaran 2014). However, as it turned out, the invasion of Iran by Iraq in 1980, reduced oil production and refining capacity significantly and actual production dropped from around 6 mbd in 1978 to averaging around $2.1 \mathrm{mbd}$ during the 1980s. What is interesting is that Figure 3 shows that the fall of Iranian supply was initially somewhat compensated for by Saudi Arabia, which increased its production by 1.6 mbd between 1978-1981.

The second major Iranian supply shock was due to a series of sanctions on Iran initiated by the U.S. in 2011 and followed by the European Union in 2012, which included (i) penalties on companies involved in Iran's upstream activities and petrochemical industry, followed by (ii) sanctions on Iran's Central Bank, to (iii) ending of financial transaction services to Iranian banks, and (iv) eventually a complete embargo on import of Iranian oil, to name a few. ${ }^{15}$ The result of these comprehensive oil (and financial) sanctions was a significant reduction in Iranian oil production and exports. According to the U.S. Energy Information Administration Iranian oil production between June 2011 and June 2014 had fallen by 875 thousand barrels per day. What is most interesting is that during the same period Saudi Arabian production had increased by 865 thousand barrels per day. Therefore, there is a clear compensating movement in Saudi oil output, when Iran's oil output falls by large amounts due to political factors. This is only possible given Saudi Arabia's position as a global swing producer, in line with what is shown in Figure 2. But note that outside these two episodes (1978/79-1981 and 2011 onwards) Iranian production remains fairly stable with the Saudi oil output being quite volatile.

Turning to the GDP effects following an Iranian oil supply shock, we notice that Iranian real output falls by $6 \%$ per annum in the short-run and $3.5 \%$ in the long run, see Figure 4. This fall is due mainly to lower production in the short run and lower oil prices in the long run, which in turn reduces Iranian oil income. It is worth noting that the ratio of Iranian oil export revenues to real output and total exports is around $22 \%$ and $70 \%$, respectively, with these ratios having been maintained over the last three decades. See, for instance, Mohaddes and Pesaran (2014). However, for Saudi Arabia the fall in oil prices is more than compensated by the increase in Saudi oil production; as a result real output increases by

\footnotetext{
${ }^{15}$ See Habibi (2014) for more details about the history of specific sanctions on Iran.
} 
$3.1 \%$ in the long run. Interestingly, for most of the other countries the median output effects are positive suggesting that the fall in oil prices has helped boost real output, although these responses are statistically insignificant. Therefore, overall our results seem to suggest that an adverse shock to Iranian oil supply is neutralized in terms of its effects on the global economy by a compensating increase in the Saudi oil production. As we have noted, this is largely borne out by the recent episode of intensification of oil sanctions against Iran.

\subsection{An adverse shock to Saudi Arabian oil supply}

Figure 5 displays the plots of structural impulse responses for the effects of a negative Saudi Arabian supply shock on oil prices as well as on global oil supply. It can be seen that Saudi production falls by $11 \%$ per quarter in the long run, although in the short-run both Iranian and Norwegian oil production increases by $4 \%$ and $2 \%$ per annum, respectively. But considering that all major producers except for Saudi Arabia are producing at or close to capacity, the fall in Saudi supply is not compensated for by the other producers in the long run. As a result oil prices increase by $22 \%$, and global equity markets fall by $9 \%$ in the long-run (with both effects being statistically significant). This large oil price effect is not surprising and even larger effects have been documented following Saudi decisions to make large changes in their production. For instance, in September 1985, Saudi production was increased from $2 \mathrm{mbd}$ to $4.7 \mathrm{mbd}$, causing oil prices to drop from $\$ 59.67$ to $\$ 30.67$ in real terms.

The effects of the negative shock to Saudi Arabian oil production on real output of the 26 countries and the euro area are shown in Figure 6. Not surprisingly, given that the increase in oil prices does not fully offset the fall in oil income due to the lower Saudi oil production, we have a negative effect on Saudi Arabian real output, which falls by $10 \%$ in the long-run (Saudi oil export revenue to GDP ratio is around 40\%). On the other hand, Iranian real GDP increases by $2 \%$ in the short-run (being statistically significant for the first five quarters) as Iranian oil production increases in the short term (see Figure 5). Turning to the (net) oil importers we notice from Figure 6 that almost all median effects are negative and more importantly significant for the following countries: Argentina (-2.9\%), Australia $(-0.6 \%)$, Chile $(-1.6 \%)$, Korea (-1.6\%), Malaysia $(-1.7 \%)$, the U.K. $(-1.0 \%)$, and the U.S. $(-0.7 \%)$, with the median annualized effects in the 16th quarter reported in the brackets. Therefore, in contrast to the Iranian case, any major cutbacks to Saudi oil production are likely to have significant ramifications on the global economy, adversely affecting real output and equity prices worldwide. 


\section{Figure 5: Structural Impulse Responses of a Negative Unit Shock to Saudi Arabian Oil Supply}
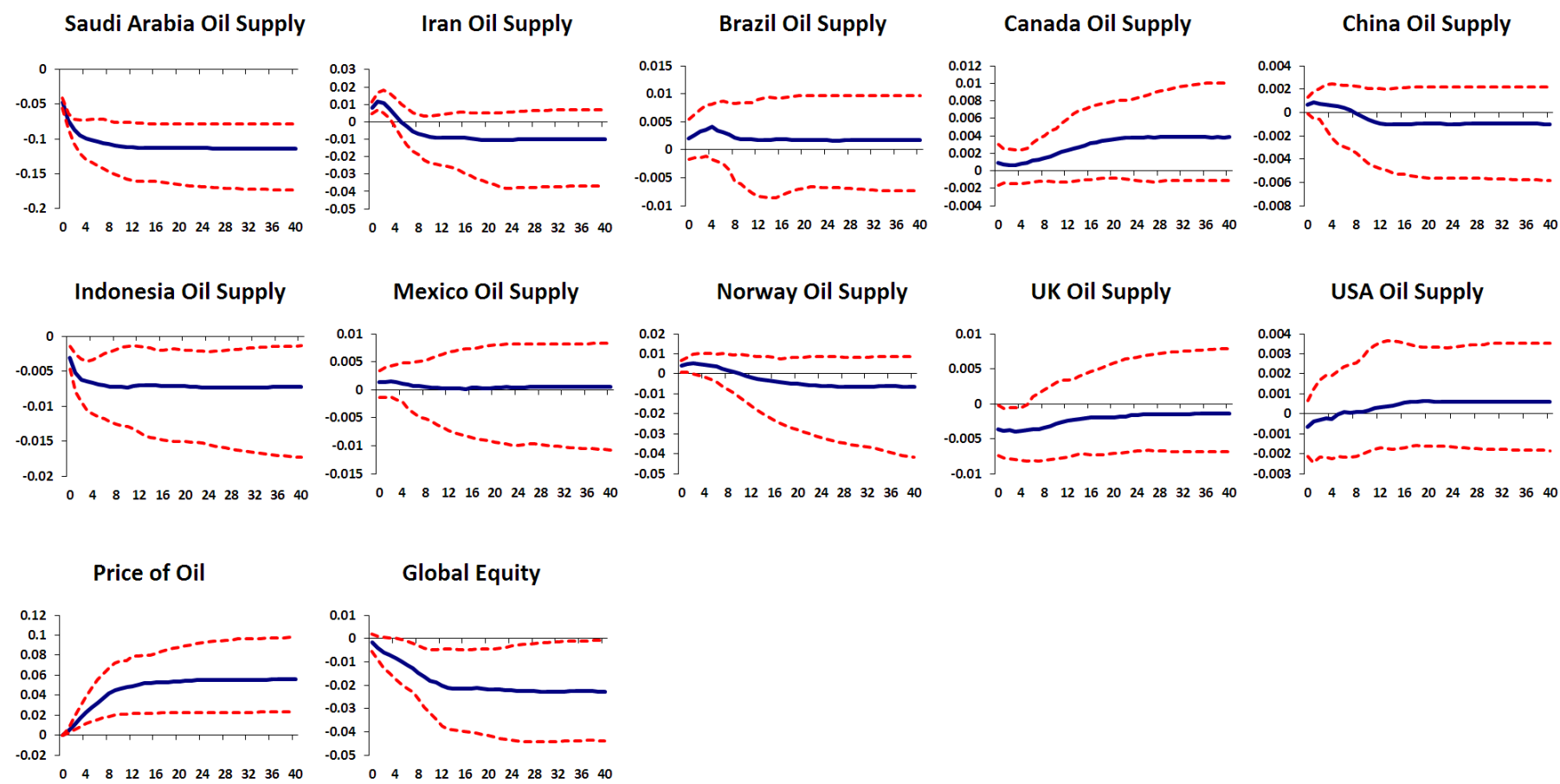

Notes: Figures show median impulse responses to a one-standard-deviation decrease in Saudi Arabian oil supply, with 95 percent bootstrapped confidence bounds. The horizon is quarterly. 


\section{Figure 6: Structural Impulse Responses of a Negative Unit Shock to Saudi Arabian Oil Supply}

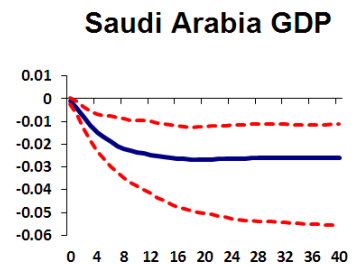

Canada GDP

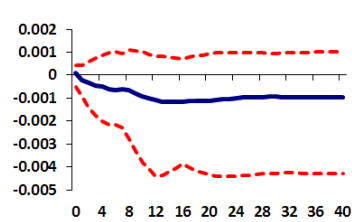

Indonesia GDP

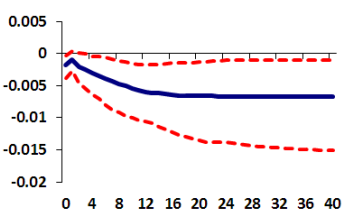

Norway GDP

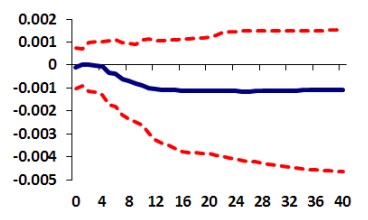

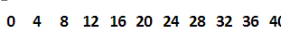

Singapore GDP

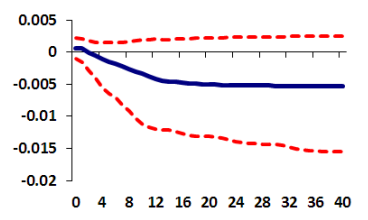

UK GDP

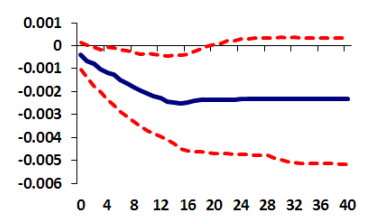

Iran GDP

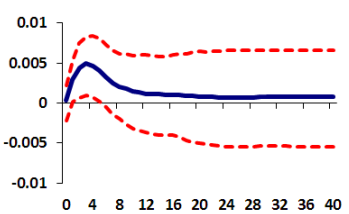

China GDP

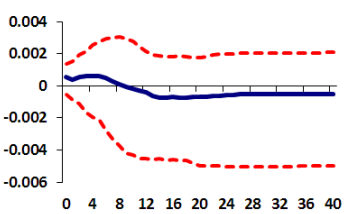

Japan GDP

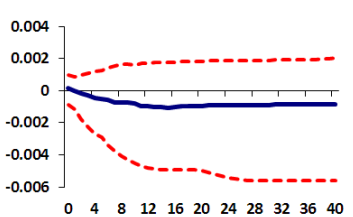

New Zealand GDP

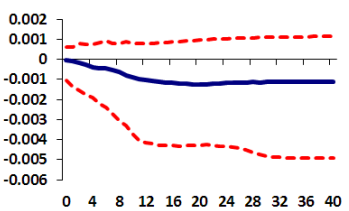

Sweden GDP

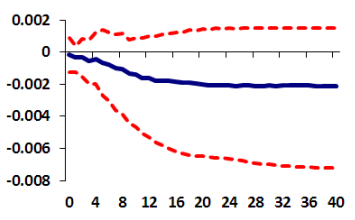

USA GDP

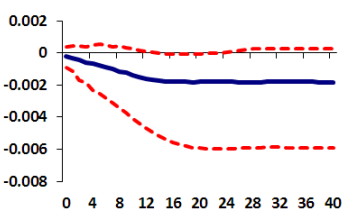

Argentina GDP

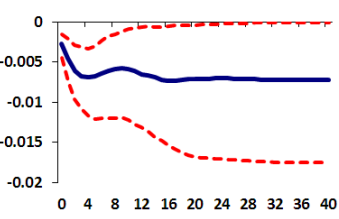

Chile GDP

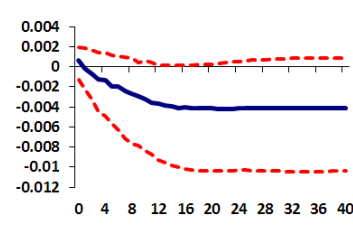

Korea GDP

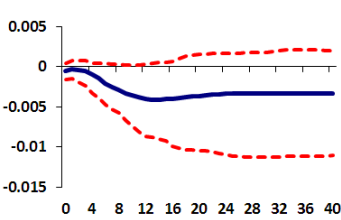

Peru GDP

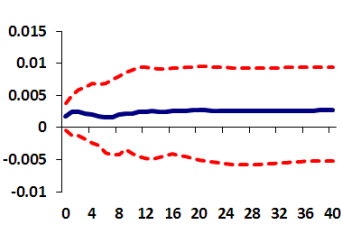

Switzerland GDP

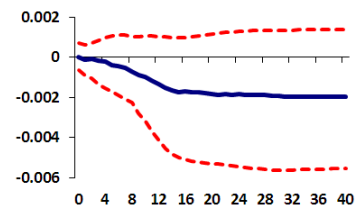

Australia GDP

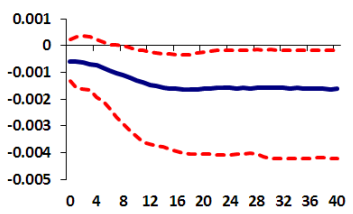

Euro Area GDP

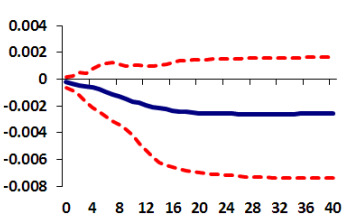

Malaysia GDP

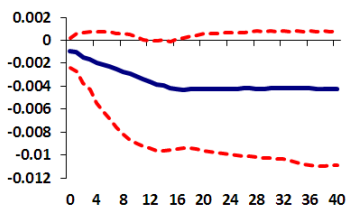

Philippines GDP

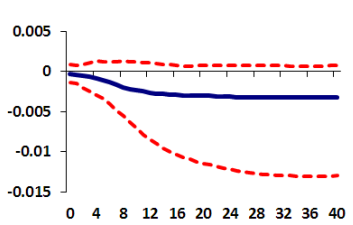

Thailand GDP

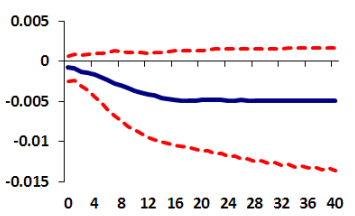

Brazil GDP

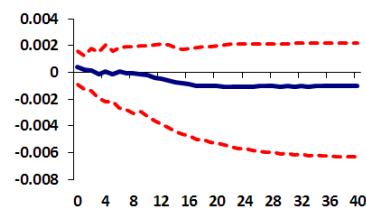

India GDP

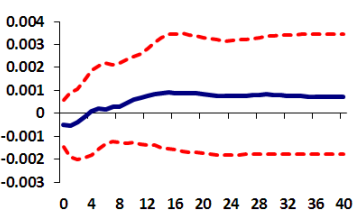

Mexico GDP

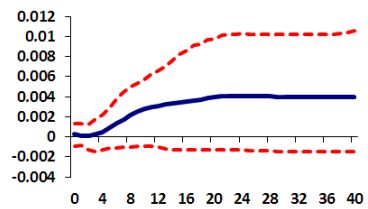

South Africa GDP

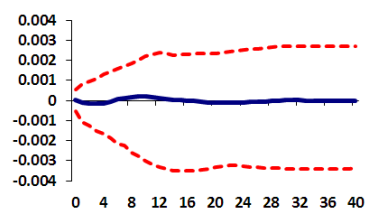

Turkey GDP

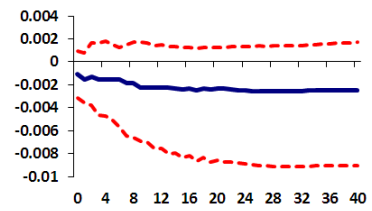

Notes: Figures show median impulse responses to a one-standard-deviation decrease in Saudi Arabian oil supply, with 95 percent bootstrapped confidence bounds. The horizon is quarterly. 


\section{Concluding remarks}

In this paper, we developed a quarterly model for oil markets, taking into account both global supply and demand conditions, which was then integrated within a compact multicountry model of the global economy utilizing the GVAR framework, creating a regionally disaggregated model of oil supply and demand. Oil supplies were determined in countryspecific models conditional on oil prices, with oil prices determined globally in terms of aggregate oil supplies and world income. The combined model, referred to as the GVAR-Oil model, was estimated using quarterly observations over the period 1979Q2-2013Q1 for 27 countries (with the euro area treated as a single economy), and tested for the key assumptions of weak exogeneity of global and country-specific foreign variables, and parameter stability. The statistical evidence provided in the appendix supports these assumptions and shows that only 11 out of the 158 tests of weak exogeneity that were carried out were statistically significant at the $5 \%$ level. Also, most regression coefficients turned out to be stable, although we found important evidence of instability in error variances which is in line with the well documented evidence on "great moderation" in the United States. To deal with changing error variances we used bootstrapping techniques to compute confidence bounds for the impulse responses that we report.

This paper contributes to the literature both in terms of the way we model oil prices and in the new approach used to identify country-specific oil supply shocks within a multi-country framework, which contrasts with the literature's focus on the analysis of global shocks. In this way we have been able to address important questions regarding the macroeconomic implications of oil supply disruptions (due to sanctions, wars or natural disasters) for the world economy on a country-by-country basis.

Our results indicate that the global economic implications of oil supply shocks vary substantially depending on which country is subject to the shock. In particular, our findings suggest that following a negative shock to Iranian oil supply, Saudi Arabian oil output increases so as to compensate for the loss in OPEC exports and to stabilize the oil markets. This is possible as Saudi Arabia has considerable spare capacity and is often seen as a global swing producer. As a result, mainly due to Iran's lower oil income, we observe a fall in Iranian real output by $6 \%$ in the short-run which then rebounds somewhat to end up $3.5 \%$ below its level before the shock. For Saudi Arabia, on the other hand, the fall in oil prices is

more than compensated for by the increase in Saudi oil production, and as a result Saudi real output increases by $3.1 \%$ in the long run. Given the increase in Saudi Arabian oil production, overall, a negative shock to Iranian oil supply is neutralized in terms of its effects on the global economy. 
In contrast the macroeconomic consequences of an adverse shock to Saudi Arabian oil production are very different from those of an Iranian oil supply shock. Given that most of the other oil producers are producing at (or near) capacity, they cannot increase their production to compensate for a loss in Saudi Arabian supply. We therefore observe an immediate and permanent increase in oil prices by $22 \%$ in the long run. As a result, such a supply shock has significant effects for the global economy in terms of real output, which falls in both advanced (including the U.K. and the U.S.) and emerging economies, and also in terms of financial markets as global equity markets fall by $9 \%$ in the long run. 


\section{References}

Andrews, D. W. K. and W. Ploberger (1994). Optimal Tests when a Nuisance Parameter is Present Only Under the Alternative. Econometrica 62(6), pp. 1383-1414.

Baumeister, C. and G. Peersman (2013a). The Role Of Time-Varying Price Elasticities In Accounting For Volatility Changes In The Crude Oil Market. Journal of Applied Econometrics 28(7), 1087-1109.

Baumeister, C. and G. Peersman (2013b). Time-Varying Effects of Oil Supply Shocks on the US Economy. American Economic Journal: Macroeconomics 5(4), 1-28.

Baxter, M. and M. A. Kouparitsas (2005). Determinants of Business Cycle Comovement: A Robust Analysis. Journal of Monetary Economics 52(1), pp. 113-157.

Blanchard, O. J. and J. Gali (2009). The Macroeconomic Effects of Oil Price Shocks: Why are the 2000s so different from the 1970s? In J. Gali and M. Gertler (Eds.), International Dimensions of Monetary Policy, pp. 373-428. University of Chicago Press, Chicago.

Cashin, P., K. Mohaddes, and M. Raissi (2015). Fair Weather or Foul? The Macroeconomic Effects of El Niño. IMF Working Paper WP/15/89.

Cashin, P., K. Mohaddes, M. Raissi, and M. Raissi (2014). The Differential Effects of Oil Demand and Supply Shocks on the Global Economy. Energy Economics 44, 113-134.

Cavalcanti, T. V. d. V., K. Mohaddes, and M. Raissi (2011a). Growth, Development and Natural Resources: New Evidence Using a Heterogeneous Panel Analysis. The Quarterly Review of Economics and Finance 51(4), 305-318.

Cavalcanti, T. V. d. V., K. Mohaddes, and M. Raissi (2011b). Does Oil Abundance Harm Growth? Applied Economics Letters 18(12), 1181-1184.

Cavalcanti, T. V. D. V., K. Mohaddes, and M. Raissi (2014). Commodity Price Volatility and the Sources of Growth. Journal of Applied Econometrics, forthcoming.

Chudik, A. and M. Fidora (2012, December). How the Global Perspective Can Help Us Identify Structural Shocks. Federal Reserve Bank of Dallas Staff Papers (12).

Chudik, A., M. H. Pesaran, and E. Tosetti (2011). Weak and Strong Cross-Section Dependence and Estimation of Large Panels. The Econometrics Journal 14(1), C45-C90. 
Dees, S., F. di Mauro, M. H. Pesaran, and L. V. Smith (2007). Exploring the International Linkages of the Euro Area: A Global VAR Analysis. Journal of Applied Econometrics 22, $1-38$.

Esfahani, H. S., K. Mohaddes, and M. H. Pesaran (2013). Oil Exports and the Iranian Economy. The Quarterly Review of Economics and Finance 53(3), 221-237.

Esfahani, H. S., K. Mohaddes, and M. H. Pesaran (2014). An Empirical Growth Model for Major Oil Exporters. Journal of Applied Econometrics 29(1), 1-21.

Fattouh, B. (2007). The Drivers of Oil Prices: The Usefulness and Limitations of NonStructural model, the Demand-Supply Framework and Informal Approaches. Oxford Institute for Energy Studies WPM 32.

Gately, D. and H. G. Huntington (2002). The Asymmetric Effects of Changes in Price and Income on Energy and Oil Demand. The Energy Journal 23(1), 19-56.

Habibi, N. (2014). Economy of Iran in Shadow of Sanctions. In P. Alizadeh and H. Hakimian (Eds.), Iran and the Global Economy: Petro Populism, Islam and Economic Sanctions, pp. 172-198. Routledge, London.

Hamilton, J. D. (2003). What is an Oil Shock? Journal of Econometrics 113(2), 363 398.

Hamilton, J. D. (2009). Causes and Consequences of the Oil Shock of 2007-08. Brookings Papers on Economic Activity, Economic Studies Program, The Brookings Institution 40(1), 215-283.

Hamilton, J. D. (2013). Historical Oil Shocks. In R. E. Parker and R. Whaples (Eds.), Routledge Handbook of Major Events in Economic History, pp. 239-265. Routledge Taylor and Francis Group, New York.

Hansen, B. (1992). Efficient Estimation and Testing of Cointegrating Vectors in the Presence of Deterministic Trends. Journal of Econometrics 53, pp. 87-121.

Harbo, I., S. Johansen, B. Nielsen, and A. Rahbek (1998). Asymptotic Inference on Cointegrating Rank in Partial Systems. Journal of Business 83 Economic Statistics 16, pp. 388-399.

Hotelling, H. (1931). The Economics of Exhaustible Resources. The Journal of Political Economy 39(2), 137-175. 
International Monetary Fund, . (2012). Chapter 4: Commodity Price Swings and Commodity Exporters. World Economic Outlook (April).

Johansen, S. (1992). Cointegration in Partial Systems and the Efficiency of Single-equation Analysis. Journal of Econometrics 52(3), pp. 389-402.

Kilian, L. (2008a). A Comparison of the Effects of Exogenous Oil Supply Shocks on Output and Inflation in the G7 Countries. Journal of the European Economic Association 6, 78-121.

Kilian, L. (2008b). Exogenous Oil Supply Shocks: How Big Are They and How Much Do They Matter for the U.S. Economy? The Review of Economics and Statistics 90, 216-240.

Kilian, L. (2009). Not All Oil Price Shocks Are Alike: Disentangling Demand and Supply Shocks in the Crude Oil Market. The American Economic Review 99(3), 1053-1069.

Kilian, L. and D. P. Murphy (2012). Why Agnostic Sign Restrictions are not Enough: Understanding the Dynamics of Oil Market VAR Models. Journal of the European Economic Association 10(5), 1166-1188.

Kilian, L. and D. P. Murphy (2014). The Role of Inventories and Speculative Trading in the Global Market for Crude Oil. Journal of Applied Econometrics 29(3), 454-478.

Kilian, L., A. Rebucci, and N. Spatafora (2009). Oil Shocks and External Balances. Journal of International Economics rry(2), 181 - 194.

Krichene, N. (2006). World Crude Oil Markets: Monetary Policy and the Recent Oil Shock. IMF Working Paper 06/62.

Lee, K. and M. H. Pesaran (1993). Persistence Profiles and Business Cycle Fluctuations in a Disaggregated Model of UK Output Growth. Ricerche Economiche 47, 293-322.

MacKinnon, J. G. (1991). Critical Values for Cointegration Tests. In R. Engle and C. Granger (Eds.), Long-Run Economic Relationships: Readings in Cointegration, Chapter 13, pp. 267-276. Oxford University Press.

Mohaddes, K. (2013). Econometric Modelling of World Oil Supplies: Terminal Price and the Time to Depletion. OPEC Energy Review 37(2), 162-193.

Mohaddes, K. and M. H. Pesaran (2014). One Hundred Years of Oil Income and the Iranian Economy: A Curse or a Blessing? In P. Alizadeh and H. Hakimian (Eds.), Iran and the Global Economy: Petro Populism, Islam and Economic Sanctions. Routledge, London. 
Nyblom, J. (1989). Testing for the Constancy of Parameters Over Time. Journal of the American Statistical Association 84(405), pp. 223-230.

Park, H. and W. Fuller (1995). Alternative Estimators and Unit Root Tests for the Autoregressive Process. Journal of Time Series Analysis 16, pp. 415-429.

Peersman, G. and I. Van Robays (2012). Cross-country Differences in the Effects of Oil Shocks. Energy Economics 34(5), pp. 1532-1547.

Pesaran, M., R. Smith, and T. Akiyama (1998). Energy Demand in Asian Developing Economies. Oxford University Press, Oxford.

Pesaran, M. H., T. Schuermann, and S. Weiner (2004). Modelling Regional Interdependencies using a Global Error-Correcting Macroeconometric Model. Journal of Business and Economics Statistics 22, 129-162.

Pesaran, M. H. and Y. Shin (1996). Cointegration and Speed of Convergence to Equilibrium. Journal of Econometrics $71,117-143$.

Pesaran, M. H. and Y. Shin (1998). Generalised Impulse Response Analysis in Linear Multivariate Models. Economics Letters 58, 17-29.

Pesaran, M. H., Y. Shin, and R. J. Smith (2000). Structural Analysis of Vector Error Correction Models with Exogenous I(1) Variables. Journal of Econometrics 97, 293-343.

Pesaran, M. H., Y. Shin, and R. J. Smith (2001). Bounds Testing Approaches to the Analysis of Level Relationships. Journal of Applied Econometrics 16, 289-326. Special issue in honour of J D Sargan on the theme 'Studies in Empirical Macroeconometrics'.

Ploberger, W. and W. Krämer (1992). The CUSUM Test with OLS Residuals. Econometrica $60(2)$, pp. 271-285.

Quandt, R. E. (1960). Tests of the Hypothesis that a Linear Regression System Obeys Two Separate Regimes. Journal of the American Statistical Association 55(290), pp. 324-330.

Rey, H. (2013). Dilemma not Trilemma: The Global Financial Cycle and Monetary Policy Independence. Jackson Hole Economic Symposium..

Smith, L. and A. Galesi (2014). GVAR Toolbox 2.0. University of Cambridge: Judge Business School. 


\section{A Data appendix}

\section{A.1 Data sources}

The main data source used to estimate the GVAR-Oil model is Smith and Galesi (2014), which provides quarterly observations for the majority of the variables covering the period 1979Q2-2013Q1. We augment this database with quarterly observations for Iran and for oil production. Data on consumer price index, GDP, and the exchange rate for Iran for the period 1979Q1-2006Q4 are from Esfahani et al. (2014). These series are updated using the Central Bank of Iran's (CBI) online database as well as several volumes of the CBI's Economic Report and Balance Sheets and Monthly CPI Workbook. The Iranian GDP data were updated using the International Monetary Fund's (IMF) International Financial Statistics and World Economic Outlook databases, while the exchange rate data are from the IMF International Financial Statistics (for the official exchange rate) and IMF INS database (for the "free market" rate). ${ }^{16}$ Finally, we obtain quarterly oil production series (in thousand barrels per day) from the U.S. Energy Information Administration International Energy Statistics. But these data are only available from 1994Q1, so quarterly series from 1979Q2 to 1993Q4 were linearly interpolated (backward) using annual series. ${ }^{17}$

\section{A.2 Construction of the variables}

Log real GDP, $y_{i t}$, the rate of inflation, $\pi_{i t}$, short-term interest rate, $r_{i t}^{S}$, long-term interest rate, $r_{i t}^{L}$, the $\log$ deflated exchange rate, $e p_{i t}$, and $\log$ real equity prices, $e q_{i t}$, are six variables included in our model, as well as most of the GVAR applications in the literature. These six variables are constructed as

$$
\begin{aligned}
& y_{i t}=\ln \left(G D P_{i t}\right), \quad \pi_{i t}=p_{i t}-p_{i t-1}, \quad p_{i t}=\ln \left(C P I_{i t}\right), \quad e p_{i t}=\ln \left(E_{i t} / C P I_{i t}\right), \\
& r_{i t}^{S}=0.25 \ln \left(1+R_{i t}^{S} / 100\right), \quad r_{i t}^{L}=0.25 \ln \left(1+R_{i t}^{L} / 100\right), \quad e q_{i t}=\ln \left(E Q_{i t} / C P I_{i t}\right)
\end{aligned}
$$

where $G D P_{i t}$ is the real Gross Domestic Product at time $t$ for country $i, C P I_{i t}$ is the consumer price index, $E_{i t}$ is the nominal exchange rate in terms of US dollar, $E Q_{i t}$ is the nominal Equity Price Index, and $R_{i t}^{S}$ and $R_{i t}^{L}$ are short-term and long-term interest rates, respectively. In addition to the above variables we also include the log of oil prices, $p_{t}^{o}$, and the log of oil production, $q_{i t}^{o}$ in our dataset.

\footnotetext{
${ }^{16}$ Data on the "free market" rate are only available from the IMF between 1979Q1 to 2011Q3. We therefore make use of data from online traders, such as Eranico: www.eranico.com, to complete the series until $2013 \mathrm{Q} 1$.

${ }^{17}$ For a description of the interpolation procedure see Section 1.1 of Supplement A of Dees et al. (2007).
} 
For Iran only, as in Esfahani et al. (2013), we construct $e p_{i t}$ as a geometrically weighted average of the $\log$ of the free $\left(e_{\text {Iran }, t}\right)$ and the official rates $\left(e_{\text {IranOF,t }}\right)$

$$
e_{\text {Iran }, \delta, t}=\delta e_{\operatorname{Iran}, t}+(1-\delta) e_{\operatorname{IranOF}, t},
$$

where $\delta$ represents the proportion of imports by public and private agencies that are traded at the free market rate, on average. There is little hard evidence on $\delta$ although, due to the gradual attempts at currency unification, it is reasonable to expect $\delta$ to have risen over time. Initially we set $\delta=0.70$, but smaller values of $\delta=0.65$ and 0.60 resulted in very similar estimates and test outcomes. We, therefore, only report the results using $e_{\operatorname{Iran}, \delta, t}$ with $\delta=0.70$.

Table 7: PPP-GDP Weights and Global Equity Weights (in percent), averages over 2007-2009

\begin{tabular}{lcclcc}
\hline Country & $\begin{array}{c}\text { PPP GDP } \\
\text { Weights }\left(w_{i}\right)\end{array}$ & $\begin{array}{c}\text { Global Equity } \\
\text { Weights }\left(w_{i}^{e q}\right)\end{array}$ & Country & $\begin{array}{c}\text { PPP GDP } \\
\text { Weights }\left(w_{i}\right)\end{array}$ & $\begin{array}{c}\text { Global Equity } \\
\text { Weights }\left(w_{i}^{e q}\right)\end{array}$ \\
\hline Argentina & 0.99 & 1.03 & Norway & 0.48 & 0.50 \\
Australia & 1.42 & 1.48 & New Zealand & 0.22 & 0.23 \\
Brazil & 3.44 & - & Peru & 0.42 & - \\
Canada & 2.25 & 2.33 & Philippines & 0.55 & 0.58 \\
China & 14.49 & - & South Africa & 0.88 & 0.91 \\
Chile & 0.42 & 0.44 & Saudi Arabia & 1.02 & - \\
Euro Area & 17.86 & 18.56 & Singapore & 0.44 & 0.46 \\
India & 6.15 & 6.39 & Sweden & 0.62 & 0.65 \\
Indonesia & 1.60 & - & Switzerland & 0.60 & 0.62 \\
Iran & 1.43 & - & Thailand & 0.95 & 0.98 \\
Japan & 7.47 & 7.76 & Turkey & 1.79 & - \\
Korea & 2.28 & 2.37 & UK & 3.87 & 5.02 \\
Malaysia & 0.67 & 0.69 & USA & 24.93 & 50.00 \\
Mexico & 2.75 & - & & & \\
& & & & & \\
\hline
\end{tabular}

Notes: The euro area block includes 8 of the 11 countries that initially joined the euro on January 1, 1999: Austria, Belgium, Finland, France, Germany, Italy, Netherlands, and Spain. Source: World Bank World Development Indicators, 2007-2009.

The world equity prices, $e q_{t}$, are computed as a weighted average of country-specific equity indices (when available), namely

$$
e q_{t}=\sum_{i=1}^{N} w_{i}^{e q} e q_{i t}, \text { with } \sum_{i=1}^{N} w_{i}^{e q}=1
$$

where $w_{i}^{e q} \geq 0$ measures the importance of each country's equity market in the global 
economy. The weight $w_{i}^{e q}$ is set to zero in the case of countries without substantial equity markets. For countries with important equity markets one possibility would be to use PPPGDP weights. But using such weights would understate the importance of the U.S. in the world equity markets which is much more substantial than the 25\% PPP-GDP weight of the United States in the world economy (see Table 7). Therefore, to reflect the relative importance of U.S. financial markets we set $w_{U S}^{e q}=0.50$ and allocate the remaining $50 \%$ of the weights to the remaining countries using PPP-GDP weights. The resultant weights, $w_{i}^{e q}$, are summarized in Table 7.

\section{A.3 Trade weights}

The trade weights, $w_{i j}$, used to calculate the five foreign variables $\left(y_{i t}^{*}, \pi_{i t}^{*}, e p_{i t}^{*}, r_{i t}^{* S}, r_{i t}^{* L}\right)$, are based on data from the International Monetary Fund's Direction of Trade Statistics database, and are given in the $27 \times 27$ matrix provided in Table 8. Based on 2007-2009 averages, the most important trading partner for Iran is the euro area, which accounts for $25 \%$ of total Iranian trade. Trade with China, India, and Korea (being 19\%, 9\%, and 12\% respectively) has increased significantly over the past two decades, emphasising the shift in Iranian trade from the west to the east. In fact more than $57 \%$ of Iran's trade is with Asian countries, although this number has probably increased substantially following the 2011 U.S. sanctions and the European Unions's oil and financial sanctions on Iran in 2012. Other countries in our sample with whom Iran's total trade is more than $5 \%$ are Japan (14\%) and Turkey (7\%), with the number in brackets being the trade shares. Comparing Saudi Arabia and Iran we see from Table 8 that although Saudi Arabia's trade with China $(12 \%)$, the euro area (16\%), Japan (16\%), and Korea (10\%) are substantial, Saudi trade is generally less concentrated on Asia and Europe with, for instance, the U.S. (19\%) being the major trading partner. 


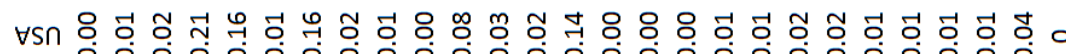

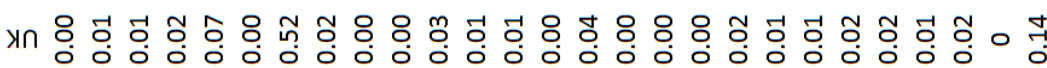

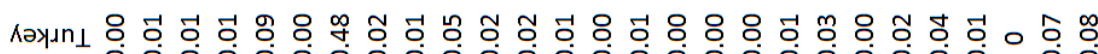

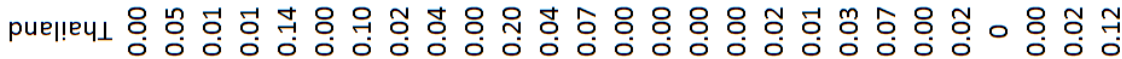

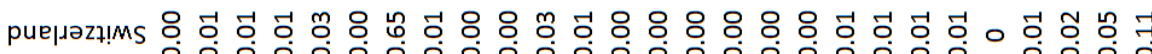

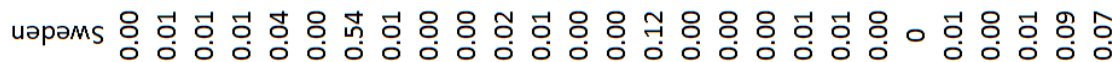

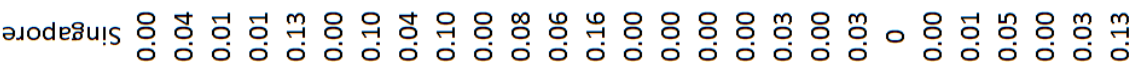

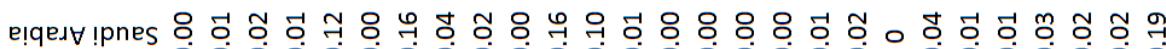

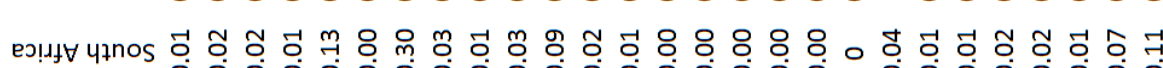

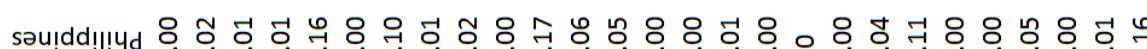

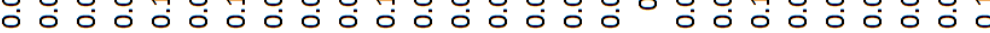

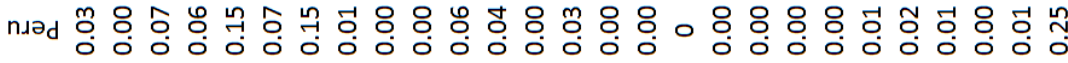

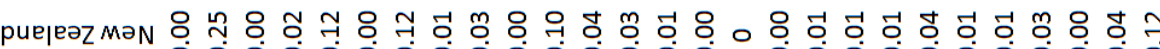

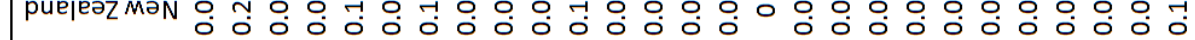

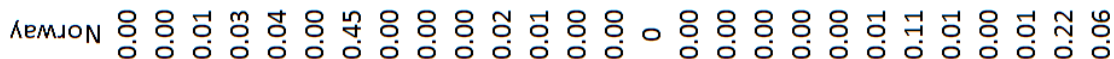

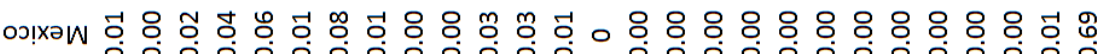

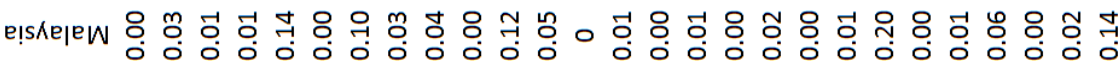

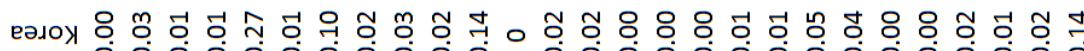

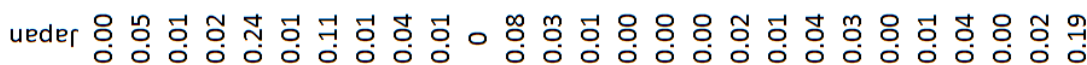

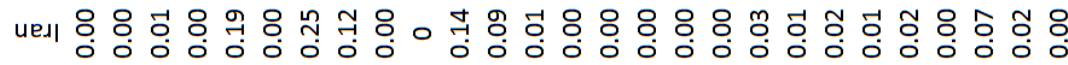

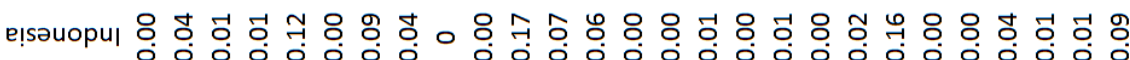

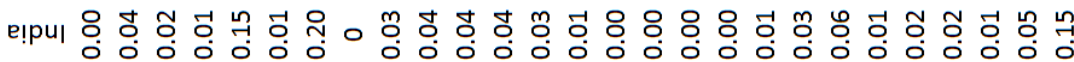

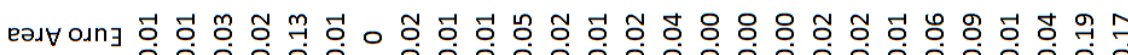

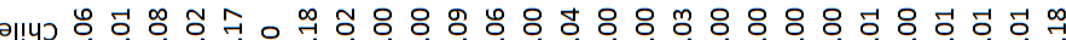

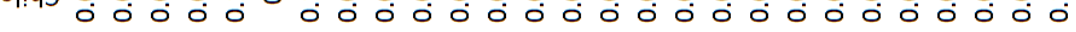

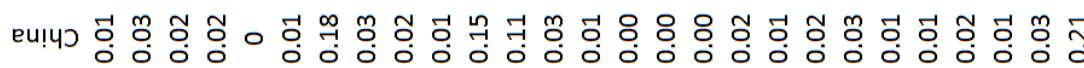

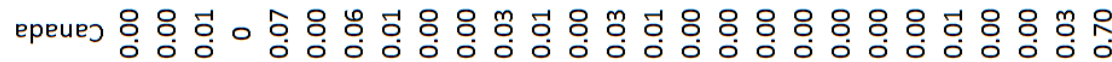

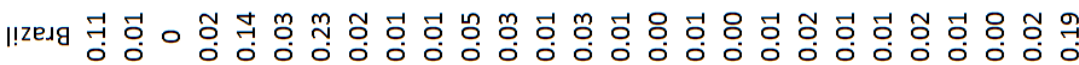

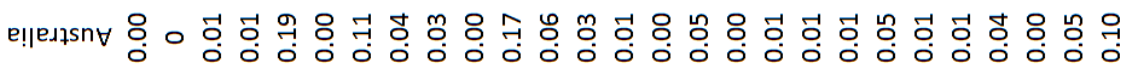
еи!ұнавя о

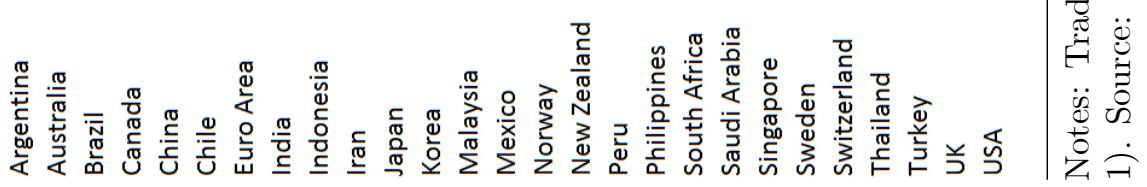




\section{B Country-specific estimates and tests}

The estimation of individual $\operatorname{VARX}^{*}\left(s_{i}, s_{i}^{*}\right)$ models is conducted under the assumption that the country-specific foreign and common variables are weakly exogenous and that the parameters of the models are stable over time. As both assumptions are needed for the construction and the implementation of the GVAR-Oil model, we will test and provide evidence for these assumptions in Sections B.2 and B.3

\section{B.1 Unit root tests}

For the interpretation of the long-run relations, and also to ensure that we do not work with a mixture of $I(1)$ and $I(2)$ variables, we need to consider the unit root properties of the core variables in our country-specific models (see Table 5). We apply Augmented Dickey-Fuller (ADF) unit root tests, as well as the weighted symmetric ADF tests (ADF-WS) proposed by Park and Fuller (1995), to the level and first differences of all the variables in the GVAR-Oil model. ${ }^{18}$ The ADF-WS tests are included as they are shown to be more powerful than the standard ADF tests in some applications. Overall, the unit root test results support the treatment of the variables in our model as being approximately $I(1)$. For brevity, these test results are not reported here but are available upon request.

\section{B.2 Testing the weak exogeneity assumption}

Weak exogeneity of country-specific foreign variables, $\mathbf{x}_{i t}^{*}=\left(y_{i t}^{*}, \pi_{i t}^{*}, e p_{i t}^{*}, r_{i t}^{* S}, r_{i t}^{* L}\right)^{\prime}$, and the common variables, $p_{t}^{\text {oil }}$ and $e q_{t}$, with respect to the long-run parameters of the conditional model is vital in the construction and the implementation of the GVAR-Oil model. We formally test this assumption following the procedure in Johansen (1992) and Harbo et al. (1998). Thus, we first estimate the $27 \operatorname{VARX}^{*}\left(s_{i}, s_{i}^{*}\right)$ models separately under the assumption that the foreign and common variables are weakly exogenous and then run the following regression for each $l$ th element of $\mathbf{x}_{i t}^{*}$

$$
\Delta x_{i t, l}^{*}=\mu_{i l}+\sum_{j=1}^{r_{i}} \gamma_{i j, l} \widehat{E C M}_{i j, t-1}+\sum_{n=1}^{p_{i}^{*}} \varphi_{i k, l}^{\prime} \Delta \mathbf{x}_{i, t-k}+\sum_{m=1}^{q_{i}^{*}} \vartheta_{i m, l} \Delta \widetilde{\mathbf{x}}_{i, t-m}^{*}+\varepsilon_{i t, l}
$$

where $\widehat{E C M}_{i j, t-1}, j=1,2, \ldots, r_{i}$, are the estimated error correction terms corresponding to the $r_{i}$ cointegrating relations found for the $i$ th country model, $p_{i}^{*}$ and $q_{i}^{*}$ are the orders of the

\footnotetext{
${ }^{18}$ All estimations and test results are obtained using the GVAR Toolbox 2.0. For further technical details see Smith and Galesi (2014).
} 
lag changes for the domestic and foreign variables, and $\Delta \widetilde{\mathbf{x}}_{i t}^{*}=\left(\Delta \mathbf{x}_{i t}^{\prime *}, \Delta e p_{i t}^{*}, \Delta p_{t}^{o i l}, \Delta e q_{t}\right)^{\prime}{ }^{19}$ Under the null hypothesis that the variables are weakly exogenous, the error correction term must not be significant; therefore, the formal test for weak exogeneity is an $F$-test of the joint hypothesis that $\gamma_{i j, l}=0$ for each $j=1,2, \ldots, r_{i}$ in equation (33).

Table 9: F-Statistics for Testing the Weak Exogeneity of the Country-Specific Foreign Variables and Oil Prices

\begin{tabular}{|c|c|c|c|c|c|c|c|c|c|}
\hline Country & F test & Critical Value & $y^{*}$ & $\Delta p^{*}$ & ep* & $r^{*}$ & Ir* & eq & poil \\
\hline Argentina & $F(2,110)$ & 3.08 & 0.96 & 1.86 & - & $3.77^{*}$ & 1.32 & 0.07 & 1.97 \\
\hline Australia & $F(2,120)$ & 3.07 & 0.41 & 2.11 & - & 0.02 & 1.35 & 0.93 & 0.12 \\
\hline Brazil & $F(2,120)$ & 3.07 & 1.16 & 0.52 & - & 1.35 & $4.28 *$ & 2.87 & 0.48 \\
\hline Canada & $F(3,118)$ & 2.68 & 2.46 & $4.60 *$ & - & 0.97 & 0.20 & 0.21 & 0.11 \\
\hline China & $F(2,108)$ & 3.08 & 0.37 & 1.09 & - & 0.02 & 0.52 & 0.21 & 0.00 \\
\hline Chile & $F(2,114)$ & 3.08 & 0.18 & 1.37 & - & 1.21 & 0.92 & 1.24 & 0.09 \\
\hline Euro Area & $F(2,121)$ & 3.07 & 1.48 & - & - & 2.37 & 0.97 & 0.29 & $3.21^{*}$ \\
\hline India & $F(1,122)$ & 3.92 & 0.26 & 0.00 & - & 2.16 & 3.21 & 0.04 & 0.01 \\
\hline Indonesia & $F(3,119)$ & 2.68 & 0.41 & 0.24 & - & 0.86 & 0.35 & 2.22 & 0.67 \\
\hline Iran & $F(1,122)$ & 3.92 & 0.14 & 0.07 & - & 1.42 & 0.18 & 1.47 & 0.00 \\
\hline Japan & $F(3,119)$ & 2.68 & $5.29 *$ & $4.55^{*}$ & - & 1.37 & 1.20 & 2.20 & $3.24 *$ \\
\hline Korea & $F(4,118)$ & 2.45 & 0.65 & 0.91 & - & 0.25 & 2.20 & 0.76 & 0.67 \\
\hline Malaysia & $F(1,115)$ & 3.92 & 0.76 & 2.25 & - & 0.95 & 0.02 & $5.78^{*}$ & 1.35 \\
\hline Mexico & $F(3,119)$ & 2.68 & 0.54 & 1.47 & - & 0.71 & 0.73 & 2.36 & 1.02 \\
\hline Norway & $F(2,119)$ & 3.07 & 2.81 & 0.02 & - & 2.25 & 0.58 & 0.12 & 0.01 \\
\hline New Zealand & $F(2,120)$ & 3.07 & 1.73 & 1.11 & - & 0.92 & 2.31 & 0.26 & 1.36 \\
\hline Peru & $F(2,121)$ & 3.07 & 0.46 & 0.05 & - & 1.07 & 1.05 & 0.70 & 1.23 \\
\hline Philippines & $F(2,121)$ & 3.07 & 1.21 & 0.38 & - & 0.25 & 0.55 & 1.70 & 2.49 \\
\hline South Africa & $F(1,121)$ & 3.92 & 0.00 & 0.09 & - & 0.01 & 0.80 & 0.69 & 1.74 \\
\hline Saudi Arabia & $F(1,111)$ & 3.93 & 1.08 & $5.66^{*}$ & - & 0.09 & 0.20 & 2.41 & 0.67 \\
\hline Singapore & $F(2,121)$ & 3.07 & 1.20 & 1.98 & - & 0.42 & $4.29 *$ & 0.53 & 0.92 \\
\hline Sweden & $F(2,120)$ & 3.07 & 2.61 & 0.40 & - & 0.05 & 1.64 & 0.71 & 0.28 \\
\hline Switzerland & $F(2,120)$ & 3.07 & 1.42 & 2.53 & - & 1.77 & 0.59 & 0.72 & 1.63 \\
\hline Thailand & $F(2,121)$ & 3.07 & 0.69 & 0.88 & - & 0.27 & 0.76 & 0.79 & 0.81 \\
\hline Turkey & $F(1,122)$ & 3.92 & 0.60 & 1.45 & - & 1.49 & 1.91 & 0.23 & 1.31 \\
\hline UK & $F(2,119)$ & 3.07 & 2.82 & 2.65 & - & 0.70 & $4.05^{*}$ & 0.16 & 3.01 \\
\hline USA & $F(3,121)$ & 2.68 & 0.38 & - & 1.17 & - & - & - & 0.89 \\
\hline
\end{tabular}

Notes: * denotes statistical significance at the $5 \%$ level.

The test results together with the $95 \%$ critical values are reported in Table 9, from which we see that the weak exogeneity assumption cannot be rejected for the overwhelming majority of the variables considered. In fact, only 11 out of 158 exogeneity tests turned out to be statistically significant at the $5 \%$ level. Considering the significance level assumed here, even if the weak exogeneity assumption is always valid, we would expect up to 8 rejections, $5 \%$ of

\footnotetext{
${ }^{19}$ Note that the models for U.S. and other oil producers are specified differently as is the model for the euro area. See the discussion in Section 4.2.
} 
the 158 tests. Therefore, overall, the available evidence in Table 9 supports our treatment of the foreign and global variables in the individual VARX* models as weakly exogenous.

\section{B.3 Tests of structural breaks}

The possibility of structural breaks is a fundamental problem in macroeconomic modelling. However, given that the individual VARX* models are specified conditional on the foreign variables in $\mathbf{x}_{i t}^{*}$, they are more robust to the possibility of structural breaks in comparison to reduced-form VARs, as the GVAR setup can readily accommodate co-breaking. See Dees et al. (2007) for a detailed discussion. We test the null of parameter stability using the residuals from the individual reduced-form error correction equations of the countryspecific $\operatorname{VARX}^{*}\left(s_{i}, s_{i}^{*}\right)$ models, initially looking at the maximal OLS cumulative sum statistic $\left(P K_{\text {sup }}\right)$ and its mean square variant $\left(P K_{m s q}\right)$ of Ploberger and Krämer (1992). We also test for parameter constancy over time against non-stationary alternatives as proposed by Nyblom (1989) $(N Y)$, and consider sequential Wald statistics for a single break at an unknown change point. More specifically, the mean Wald statistic of Hansen (1992) (MW), the Wald form of the Quandt (1960) likelihood ratio statistic $(Q L R)$, and the Andrews and Ploberger (1994) Wald statistics based on the exponential average $(A P W)$. Finally, we also examine the heteroskedasticity-robust versions of $N Y, M W, Q L R$, and $A P W$.

Table 10 presents the number of rejections of the null hypothesis of parameter constancy per variable across the country-specific models at the $5 \%$ significance level. For brevity, test statistics and bootstrapped critical values are not reported here but are available on request. Overall, it seems that most regression coefficients are stable, although the results vary considerably across different tests. In the case of the two $P K$ tests, the null hypothesis is rejected between $13 \%-16 \%$ of the time. For the $N Y, M W, Q L R$, and $A P W$ tests on the other hand, we note that the rejection rate is much larger, between $16 \%-53 \%$. The $Q L R$ and $A P W$ rejection rates, for the joint null hypothesis of coefficient and error variance stability, are particularly high with 68 cases each out of 179 being rejected. However, looking at the robust version of these tests, we note that the rejection rate falls considerably to between $9 \%$ and $16 \%$. Therefore, although we find some evidence for structural instability, it seems that possible changes in error variances rather than parameter coefficients is the main reason for this. We deal with this issue by using bootstrapped means and confidence bounds when undertaking the impulse response analysis. Table 11 presents the break dates with the QLR statistics at the $5 \%$ significance level. 
Table 10: Number of Rejections of the Null of Parameter Constancy per Variable across the Country-specific Models at the 5 percent Significance Level

\begin{tabular}{lcccccccr}
\hline Tests & $y$ & $\pi$ & $e p$ & $r^{S}$ & $r^{L}$ & $q^{\text {oil }}$ & $e q$ & Total \\
\hline & & & & & & & & \\
$P K_{\text {sup }}$ & 3 & 4 & 3 & 5 & 1 & 4 & 0 & $20(16)$ \\
$P K_{\text {msq }}$ & 3 & 3 & 3 & 4 & 0 & 4 & 0 & $17(13)$ \\
$N Y$ & 1 & 6 & 7 & 2 & 3 & 1 & 0 & $20(16)$ \\
robust- $N Y$ & 0 & 3 & 3 & 0 & 3 & 2 & 0 & $11(9)$ \\
$Q L R$ & 11 & 17 & 10 & 19 & 7 & 3 & 1 & $68(53)$ \\
robust- $Q L R$ & 1 & 6 & 2 & 3 & 6 & 2 & 0 & $20(16)$ \\
$M W$ & 7 & 9 & 10 & 7 & 7 & 2 & 1 & $43(34)$ \\
robust- $M W$ & 2 & 3 & 4 & 0 & 5 & 3 & 0 & $17(13)$ \\
$A P W$ & 11 & 17 & 11 & 19 & 7 & 3 & 0 & $68(53)$ \\
robust- $A P W$ & 1 & 5 & 3 & 1 & 6 & 3 & 0 & $19(15)$ \\
& & & & & & & & \\
\hline
\end{tabular}

Notes: The test statistics $P K_{\text {sup }}$ and $P K_{m s q}$ are based on the cumulative sums of $O L S$ residuals, $N Y$ is the Nyblom test for time-varying parameters and $Q L R, M W$ and $A P W$ are the sequential Wald statistics for a single break at an unknown change point. Statistics with the prefix 'robust' denote the heteroskedasticityrobust version of the tests. All tests are implemented at the $5 \%$ significance level. The number in brackets are the percentage rejection rates.

Table 11: Break Dates Computed with Quandt's Likelihood Ratio Statistic

\begin{tabular}{|c|c|c|c|c|c|c|c|}
\hline Country & $\mathrm{y}$ & $\Delta p$ & ep & $r$ & Ir & qoil & eq \\
\hline Argentina & 1999Q1 & 1989Q2 & 1989Q3 & 1989Q4 & - & - & - \\
\hline Australia & $1992 Q 2$ & $1984 Q 3$ & 1997Q3 & 1986Q2 & 1989Q1 & - & - \\
\hline Brazil & $1984 Q 3$ & 1989Q4 & 1998Q4 & 1989Q4 & - & $2008 Q 1$ & - \\
\hline Canada & $1987 Q 3$ & 1999Q2 & $2002 Q 4$ & 1987Q1 & 1985Q2 & $2007 Q 3$ & - \\
\hline China & $1994 Q 4$ & 1990Q1 & $1994 Q 4$ & 1990Q1 & - & 1985Q1 & - \\
\hline Chile & $1984 Q 4$ & 1985Q2 & $2003 Q 3$ & 1984Q3 & - & - & - \\
\hline Euro Area & $1987 Q 4$ & $2002 Q 3$ & 1999Q3 & 1986Q1 & 1986Q2 & - & - \\
\hline India & 1997Q2 & $1995 Q 4$ & 1991Q3 & 1994Q3 & - & - & - \\
\hline Indonesia & 1985Q4 & 1996Q1 & 1998Q1 & 1997Q2 & - & 1986Q1 & - \\
\hline Iran & 1993Q1 & 1989Q4 & $1992 Q 4$ & - & - & 1985Q1 & - \\
\hline Japan & $1989 Q 4$ & 1986Q2 & 1987Q2 & 1985Q4 & 1996Q4 & - & - \\
\hline Korea & $1984 Q 4$ & 1985Q1 & 1997Q2 & 1997Q3 & 1984Q4 & - & - \\
\hline Malaysia & 1994Q1 & $2008 Q 1$ & 1997Q2 & 1998Q2 & - & - & - \\
\hline Mexico & 1987Q1 & 1989Q2 & $1984 Q 4$ & 1988Q1 & - & $1990 Q 4$ & - \\
\hline Norway & 1984Q3 & $2002 Q 3$ & 2006Q1 & 1993Q1 & $1992 Q 3$ & $2001 Q 3$ & - \\
\hline New Zealand & 1986Q4 & 1987Q2 & 1987Q4 & 1987Q3 & 1986Q4 & - & - \\
\hline Peru & $1990 Q 4$ & $1990 Q 4$ & 1991Q2 & 1990Q1 & - & - & - \\
\hline Philippines & $1984 Q 3$ & 1991Q1 & $1984 Q 3$ & 1986Q4 & - & - & - \\
\hline South Africa & 1985Q1 & 1986Q2 & 1987Q1 & $1984 Q 3$ & 1984Q3 & - & - \\
\hline Saudi Arabia & 1989Q2 & $1992 Q 3$ & $1987 Q 4$ & - & - & 1986Q1 & - \\
\hline Singapore & $2000 Q 4$ & $1984 Q 4$ & $1984 Q 3$ & 1984Q4 & - & - & - \\
\hline Sweden & 1984Q3 & 1991Q2 & 2000Q1 & 1985Q3 & 1988Q3 & - & - \\
\hline Switzerland & $2007 Q 4$ & 1986Q1 & 1986Q4 & 1984Q4 & $2002 Q 4$ & - & - \\
\hline Thailand & $2007 Q 4$ & 1986Q1 & 1997Q4 & 1994Q4 & - & - & - \\
\hline Turkey & $1993 Q 2$ & 1994Q1 & $1992 Q 3$ & 1993Q2 & - & - & - \\
\hline UK & $1984 Q 4$ & 1993Q2 & $2004 Q 1$ & 1987Q2 & $1984 Q 3$ & 1999Q3 & - \\
\hline USA & 1984Q3 & 2003Q1 & - & 1984Q4 & 1984Q3 & $2005 Q 4$ & 199802 \\
\hline
\end{tabular}

45

Notes: All tests are implemented at the $5 \%$ significance level. 